\title{
Applying ANN, ANFIS, and LSSVM Models for Estimation of Acid Solvent Solubility in Supercritical $\mathrm{CO}_{2}$
}

\author{
Amin Bemani ${ }^{1}$, Alireza Baghban ${ }^{2}$, Shahaboddin Shamshirband ${ }^{3,4}$ \\ ${ }^{1}$ Petroleum engineering department, Petroleum university of technology, Ahwaz, Iran \\ ${ }^{2}$ Chemical engineering department, Amirkabir university of technology, Mahshahr Campus, \\ Mahshahr, Iran \\ ${ }^{3}$ Department for Management of Science and Technology Development, Ton Duc Thang \\ University, Ho Chi Minh City, Viet Nam \\ ${ }^{4}$ Faculty of Information Technology, Ton Duc Thang University, Ho Chi Minh City, Viet Nam
}

\begin{abstract}
In the present work, a novel and the robust computational investigation is carried out to estimate solubility of different acids in supercritical carbon dioxide. Four different algorithms such as radial basis function artificial neural network, Multi-layer Perceptron artificial neural network, Least squares support vector machine and adaptive neuro-fuzzy inference system are developed to predict the solubility of different acids in carbon dioxide based on the temperature, pressure, hydrogen number, carbon number, molecular weight, and acid dissociation constant of acid. In the purpose of best evaluation of proposed models, different graphical and statistical analyses and also a novel sensitivity analysis are carried out. The present study proposed the great manners for best acid solubility estimation in supercritical carbon dioxide, which can be helpful for engineers and chemists to predict operational conditions in industries.
\end{abstract}

Keywords: Supercritical carbon dioxide, Modeling, Acid, Artificial intelligence, Solubility

\footnotetext{
* Corresponding author

S.Shamshirband ( shahaboddin.shamshirband@tdtu.edu.vn)
} 


\section{Introduction}

In the recent years, supercritical fluid has become one of the interests of chemical engineers and chemists as a novel and extensive applicable technology. The synthesis and generating of nanomaterials and extraction process of different materials are the popular applications of supercritical fluids [1-13]. One of the supercritical fluids which have wide applications in the extraction of various metals from solid and liquid phases [14-16]. Due to non-flammability, nontoxicity, low cost and critical points (304.2 $\mathrm{K}$ and $7.38 \mathrm{MPa})$ of carbon dioxide, the supercritical carbon dioxide becomes one the interesting and applicable supercritical fluids in industries $[17,18]$. The viscosity and density of supercritical carbon dioxide are known as two important transport properties of the fluids which are affected by pressure and temperature. Another dominant thermos physical property of supercritical carbon dioxide is solubility of different materials in supercritical carbon dioxide which is a function of various factors such as polarity, molecular weight, pressure, temperature and vapor pressure[19, 20].

One types of the materials which have a solubility in supercritical carbon dioxide are acids, the nanofluoropentanoic acid which is known as one type of perfluorocarboxylic acids, has extensive applications in the production of paints additives, polymers, foams and stain repellents but because of their high ability instability they are harmful to environment[21-27]. Adrien Dartiguelongue and coworkers studied solubility of perfluoropentanoic acid in supercritical carbon dioxide in the wide range of temperature and pressure and also proposed some density based models to predict solubility in terms of density of supercritical fluids [22]. Gurdial et al. constructed dynamic setup to study solubility of o-, m- and p-hydroxybenzoic acid in the supercritical carbon dioxide in the wide range pressure of 80-205 mbar and temperature range of 35-55 C and correlated the measured solubility as a function of density[28]. Kumoro measured the solubility of $2 \mathrm{R}, 3 \beta$-dihydroxyurs- 
12-en-28-oic acid which is called Corosolic acid dynamically in a different range of pressure 8 to $30 \mathrm{MPa}$ and five different temperatures of 308.15, 313.15, 323.15 and 333.15 K. Kumoro used various density based models to correlate the experimental data[29].

Sahihi et al. measured the solubility of Maleic acid in supercritical carbon dioxide by utilization of static experimental setup. The measured data belongs to Maleic acid in pressure range of 7 to $30 \mathrm{MPa}$ and temperature of $348.15 \mathrm{~K}$ [30]. Ghaziaskar and coworkers used a continuous flow set up to study solubility of tracetin, diacentin and acetic acid in supercritical carbon dioxide in the pressure range of 70 to 180 bar and various temperature of 313,333 and $348 \mathrm{~K}$ and they also compared the obtained solubilities for different acids[31]. Helena Sovova adjusted the Adachi-Lu equation based on the solubility of Ribes nigrum (blackcurrant) and Vitis vinifera (grape-vine) in supercritical carbon dioxide. They concluded the Adachi-Lu equation has enough accuracy in forecasting solubility of triglycerides in carbon dioxide[32].

The issue of prediction of various acids solubility in supercritical carbon dioxide and phase equilibrium investigation of supercritical carbon dioxide and different materials are the important topics in chemical engineering research. According to the hardships of experimental studies such as special tools and procedure which are needed, in the present work, the mathematical investigation is considered as a great solution for these problems. In this paper four different algorithms, Radial basis function artificial neural network (RBF-ANN), Multi-layer Perceptron artificial neural network (MLP-ANN), Least squares support vector machine (LSSVM) and Adaptive neuro-fuzzy inference system (ANFIS) are developed to predict the solubility of different types of acid in supercritical carbon dioxide based on the various parameters such as structure of acid, pressure and temperature. 


\section{Methodology}

\subsection{Experimental Data Gathering}

The dominant purpose of present paper is development of accurate and simple models to forecast solubility of different acids in supercritical carbon dioxide. Due to this, the required actual data for training and testing phases of models were assembled from the reliable source existed in literature $[22,28,29,32-35]$. This collection of data contains the 180 acid solubility data points in terms of pressure, temperature and different acid structure. The details of data collection are reported in Table S1. Also, for clarification of this experimental dataset, the structure, linear formula and molecular weight of utilized acids are presented in Table S2.

Table S1. Experimental data which are used in this study

\begin{tabular}{|c|c|c|c|c|c|c|}
\hline Acid name & Pressure & $\begin{array}{l}\text { Temperature } \\
\text { (K) }\end{array}$ & $\begin{array}{l}\text { Acid } \\
\text { dissociation } \\
\text { constant } \\
\text { (PKa) }\end{array}$ & $\begin{array}{l}\text { solubility } \\
\text { (mol/mol) }\end{array}$ & $\begin{array}{l}\text { No of } \\
\text { data } \\
\text { points }\end{array}$ & References \\
\hline $\begin{array}{l}\text { Perfluoropentanoic } \\
\text { acid }\end{array}$ & $10-26.2$ & $314-334$ & 0.52 & $0.0134-0.0298$ & 17 & $\begin{array}{l}\text { (Dartiguelongue } \\
\text { et al., 2016) }\end{array}$ \\
\hline o-Hydroxybenzoic & $8.11-$ & $308.15-$ & 4.06 & $0.000007-$ & 49 & (Gurdial and \\
\hline Acid & 20.26 & 328.15 & & 0.000624 & & Foster, 1991) \\
\hline Corosolic Acid & $8.0-30$ & $\begin{array}{l}308.15- \\
333.15\end{array}$ & 4.7 & $\begin{array}{l}3.28 * 10^{-11}- \\
0.071\end{array}$ & 40 & (Kumoro, 2011) \\
\hline Maleic Acid & $7.0-30$ & $\begin{array}{l}318.15- \\
348.15\end{array}$ & 1.83 & $\begin{array}{l}0.000013- \\
0.0005917\end{array}$ & 21 & $\begin{array}{l}\text { (Sahihi et al., } \\
\text { 2010) }\end{array}$ \\
\hline Ferulic Acid & $12.0-28$ & $\begin{array}{l}301.15- \\
333.15\end{array}$ & 4.38 & $\begin{array}{l}0.00000155- \\
0.0000118\end{array}$ & 18 & $\begin{array}{l}\text { (Sovova et al., } \\
\text { 2001) }\end{array}$ \\
\hline
\end{tabular}




\begin{tabular}{|c|c|c|c|c|c|c|}
\hline Azelaic Acid & $10.0-30$ & $\begin{array}{l}313.15- \\
333.15\end{array}$ & 4.84 & $\begin{array}{l}0.00000042- \\
0.00001012\end{array}$ & 14 & $\begin{array}{l}\text { (Sparks et al., } \\
2007)\end{array}$ \\
\hline Nonanoic Acid & $10.0-30$ & $\begin{array}{l}313.15- \\
333.15\end{array}$ & 4.96 & $\begin{array}{l}0.00013- \\
0.00782\end{array}$ & 14 & $\begin{array}{l}\text { (Sparks et al., } \\
\text { 2008) }\end{array}$ \\
\hline $\begin{array}{l}\text { p-aminobanzoic } \\
\text { acid }\end{array}$ & $8.0-21$ & $308-328.0$ & 4.78 & $\begin{array}{l}0.000001302- \\
0.000006452\end{array}$ & 15 & $\begin{array}{l}\text { (Tian et al., } \\
\text { 2007) }\end{array}$ \\
\hline & & & & & Total $=188$ & \\
\hline
\end{tabular}

Table S2. Details of acids which are utilized in this investigation.

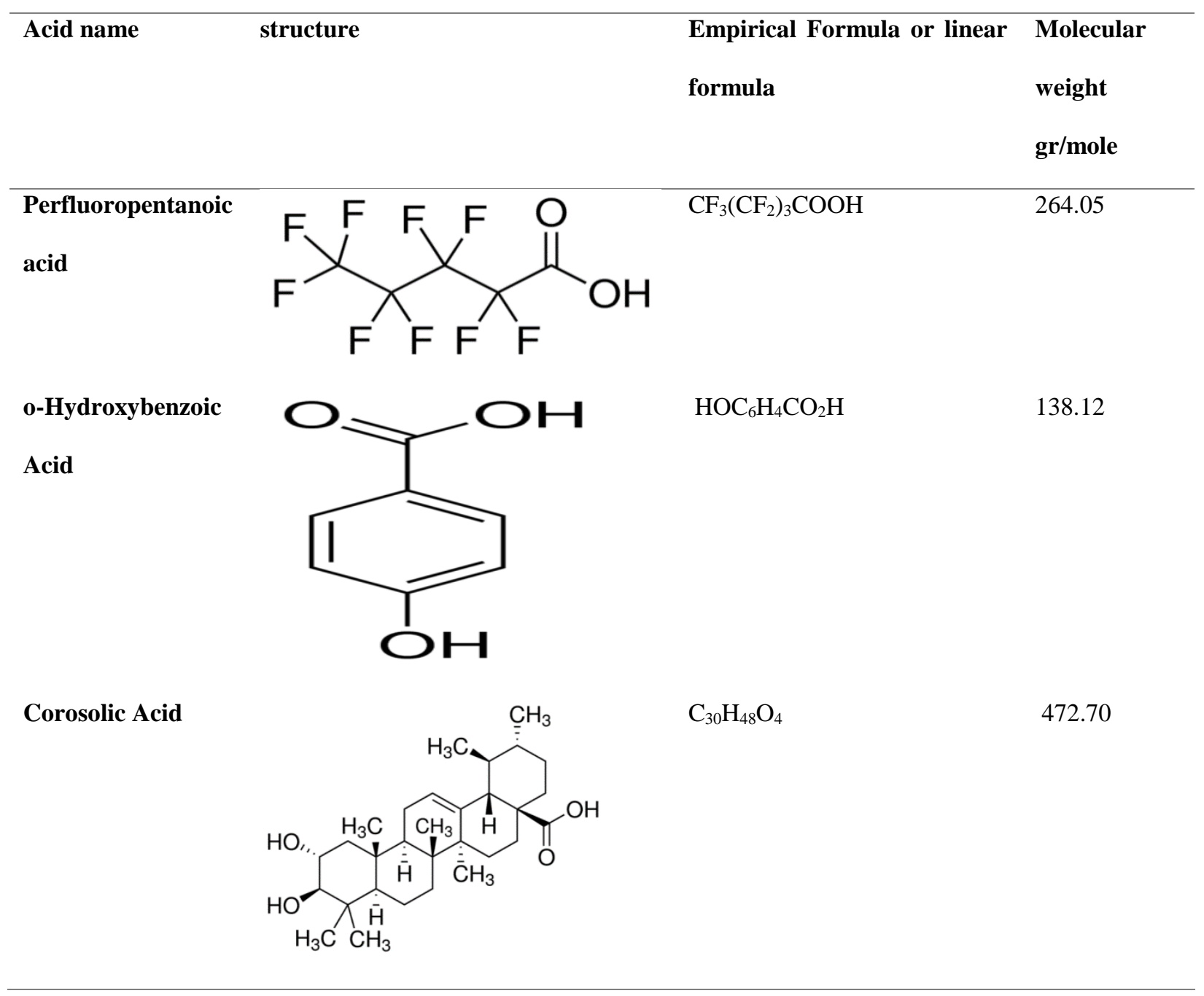




\section{Maleic Acid}<smiles>O=C(O)/C=C\C(=O)O</smiles>

Ferulic Acid<smiles>COc1cc(/C=C/C(=O)O)ccc1O</smiles>

Azelaic Acid<smiles>O=C(O)CCCCCCCC(=O)O</smiles>

Nonanoic (Sparks

et al., 2008) Acid

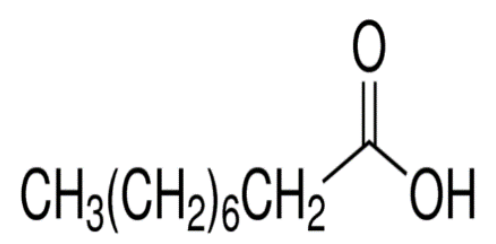

p-aminobanzoic

acid

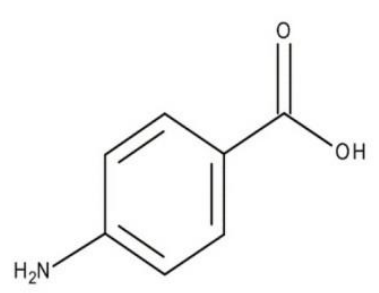

$\mathrm{HO}_{2} \mathrm{CCH}=\mathrm{CHCO}_{2} \mathrm{H}$

$\mathrm{HOC}_{6} \mathrm{H}_{3}\left(\mathrm{OCH}_{3}\right) \mathrm{CH}=\mathrm{CHCO}_{2} \mathrm{H} \quad 194.18$

$\mathrm{HO}_{2} \mathrm{C}\left(\mathrm{CH}_{2}\right)_{7} \mathrm{CO}_{2} \mathrm{H}$

188.22

$\mathrm{CH}_{3}\left(\mathrm{CH}_{2}\right)_{7} \mathrm{COOH}$

158.24

$\mathrm{C}_{7} \mathrm{H}_{7} \mathrm{NO}_{2}$

137.14

\subsection{Artificial neural network}

Artificial neural networks have amazing similarities to the performance and structure of neuron units in the brain system[36, 37]. These computational blocks construct different types of layer such as input, output and hidden layers. In the layers, there are transfer functions or activation 
function which organize the process of training in the algorithm. Each neuron has specific weight and bias values which control the optimization process. Artificial neural network has ability of tracing a nonlinear form relationship between input and output parameters. Due to this ability, artificial neural networks have widespread application in different industries and sciences [38-44].

Artificial neural networks can be classified in different forms such as a recurrent neural network (RNN), radial basis function and multilayer perceptron $[45,46]$. In the present work, the MLP and RBF network are utilized.

\subsection{Least squares support vector machine}

Vapnik organized support vector machine based on statistical learning theory[47]. This computational intelligence can be used for regression and classification purposes. However, there are many advantages to this method but there is a hardship in its computational procedure because of quadratic programming. The least squares SVM (LSSVM) is proposed as a novel type of SVM to solve this problem. This novel approach organized linear equations for computation and optimization[48-50].

By considering a dataset of $\left(\mathrm{x}_{\mathrm{i}}, \mathrm{y}_{\mathrm{i}}\right)_{\mathrm{n}}$, the LSSVM regression prediction is utilized to estimate a function, where $\mathrm{x}_{\mathrm{i}}$ and $\mathrm{y}_{\mathrm{i}}$ are known as input and target parameters and $\mathrm{n}$ represent the number of data which utilized in training phase[51]. The linear regression is formulated such as following:

$y=\omega^{T} \varphi(\mathrm{x})+\mathrm{b}$

Where $\varphi(\mathrm{x})$ denotes a nonlinear function that has different forms such as polynomial, linear, sigmoid and radial basis functions. Also, $\omega$ and $\mathrm{b}$ denote the weights and determined constant 
coefficient in training process. A new optimization problem can be defined based on LSSVM approach[52]:

$\frac{\min }{\omega, b, e} J(\omega, e)=\frac{1}{2} \omega^{T} \omega+\frac{1}{2} \gamma \sum_{k=1}^{N} e_{k}^{2}$

Which is related to the below constraints:

$y_{k}=\omega^{T} \varphi\left(x_{k}\right)+b+e_{k} \quad \mathrm{k}=1,2, \ldots, \mathrm{N}$

The Lagrangian equation is constructed to solve the optimization problem:

$\mathrm{L}(\omega, \mathrm{b}, \mathrm{e}, \alpha)=J(\omega, e)-\sum_{k=1}^{N} \alpha_{k}\left\{\omega^{T} \varphi\left(x_{k}\right)+b+e_{k}-y_{k}\right\}$

Where $\curlyvee$ and $e_{k}$ are known as regularization parameter and regression error. The $\alpha_{k}$ represent the support value. To solve the above problem, the above equation is differentiated with respect to the different parameters:

$\frac{\partial L(\omega, \mathrm{b}, \mathrm{e}, \alpha)}{\partial \omega}=0 \rightarrow \omega=\sum_{k=1}^{N} \alpha_{k} \varphi\left(x_{k}\right)$

$\frac{\partial L(\omega, \mathrm{b}, \mathrm{e}, \alpha)}{\partial b}=0 \rightarrow \sum_{k=1}^{N} \alpha_{k}=0$

$\frac{\partial L(\omega, \mathrm{b}, \mathrm{e}, \alpha)}{\partial e_{k}}=0 \rightarrow \alpha_{k}=\gamma e_{k}, \quad \mathrm{k}=1,2, \ldots, \mathrm{N}$

$\frac{\partial L(\omega, \mathrm{b}, \mathrm{e}, \alpha)}{\partial \alpha_{k}}=0 \rightarrow y_{k}=\omega^{T} \varphi\left(x_{k}\right)+b+e_{k} \quad \mathrm{k}=1,2, \ldots, \mathrm{N}$

Karush- Kuhn-Trucker matrix can be obtained by elimination of $\omega$ and e[50, 53, 54]:

$\left[\begin{array}{cc}0 & 1_{v}^{T} \\ 1_{v} & \Omega+\gamma^{-1} I\end{array}\right]\left[\begin{array}{l}b \\ \alpha\end{array}\right]=\left[\begin{array}{l}0 \\ y\end{array}\right]$ 
Which $y=\left[y_{1} \ldots y_{N}\right]^{T}, \alpha=\left[\alpha_{1} \ldots \alpha_{N}\right]^{T}, 1_{N}=[1 \ldots 1]^{T}$ and I represents the identity matrix. $\boldsymbol{\Omega}_{\mathrm{kl}}$ is $\varphi\left(x_{k}\right)^{T} \varphi\left(x_{l}\right)=K\left(x_{k}, x_{l}\right) . \mathrm{K}\left(\mathrm{x}_{\mathrm{k}}, \mathrm{x}_{\mathrm{l}}\right)$ is known as kernel function which can be in different forms of linear, polynomial and radial basis function forms[55]. The estimating function form of LSSVM algorithm can be expressed as following formulation[56]:

$y(x)=\sum_{k=1}^{N} \alpha_{k} K\left(x, x_{k}\right)+b$

Eq. (10)

\subsection{Adaptive neuro-fuzzy inference system (ANFIS)}

Adaptive neuro-fuzzy inference system which is called ANFIS algorithm, in brief, has five different layers. The aforementioned approach was developed by Jang and Sun[57]. The hybrid learning approach and back propagation are known as fundamentals of training of conventional ANFIS algorithm. The ANFIS algorithm was born base on fuzzy logic and neural network advantages and also the different evolutionary methods such as Imperialist Competitive Algorithm (ICA), Particle Swarm Optimization (PSO) and Genetic algorithm (GA) can be used to reach the optimal structure of ANFIS algorithm[38, 40, 58-61]. The ANFIS structure is demonstrated in Figure 1. As shown there are two input variables and an output. 


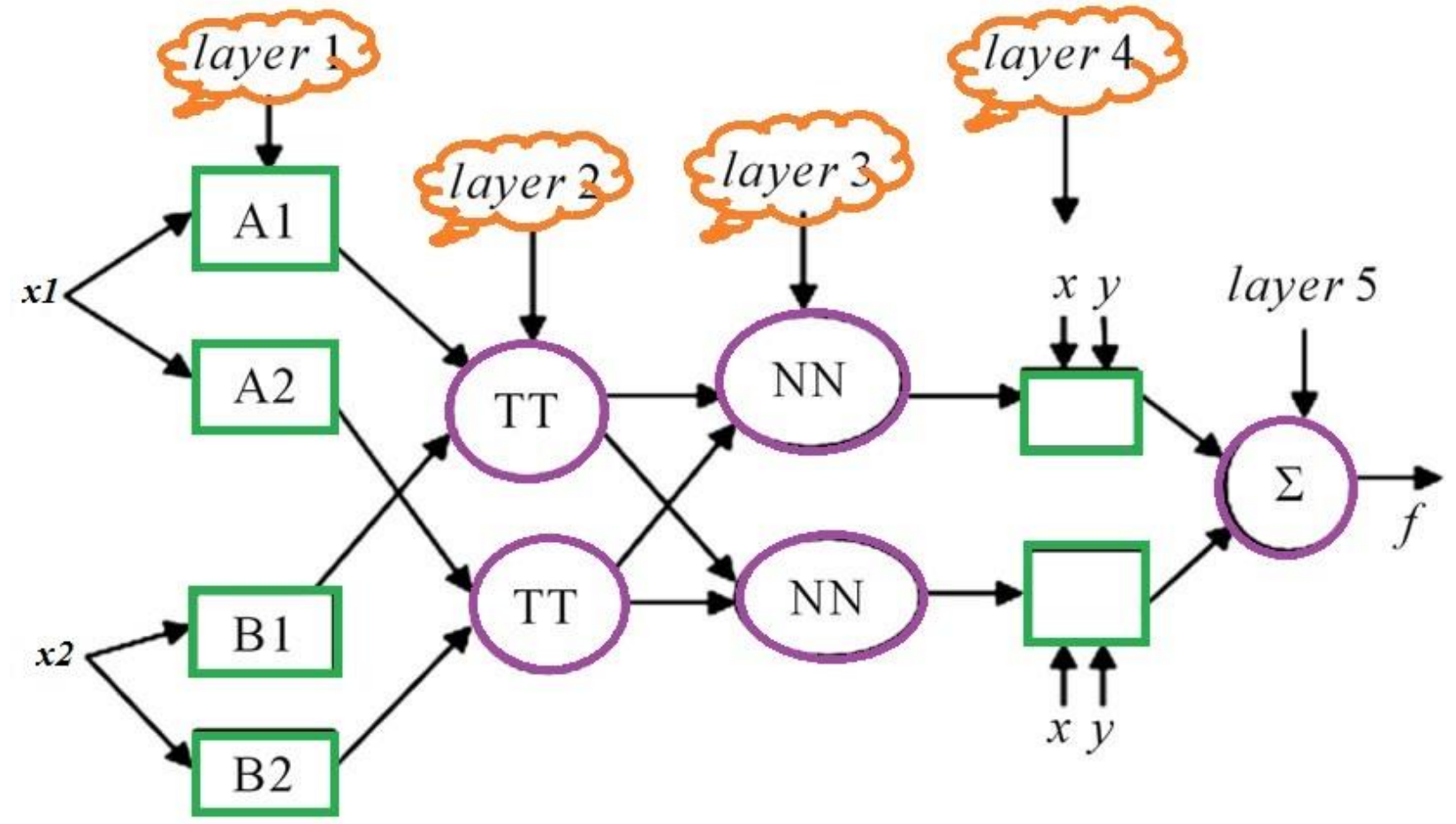

Figure 1: Typical construction of ANFIS approach

In the first layer, the linguistic terms are build base on input data. The Gaussian membership function is applied to organize these linguistic terms. The Gaussian function can be shown as following formulation[62]:

$O_{i}^{1}=\beta(X)=\exp ^{\left(-\frac{1}{2} \frac{(X-Z)^{2}}{\sigma^{2}}\right)}$

Where $\mathrm{Z}$ and $\sigma$ denote the Gaussian parameters.

The next layer contains the weighted terms which are related to rules:

$O_{i}^{2}=W_{i}=\beta_{A i}(X) \cdot \beta_{B i}(X)$

In the third layer the averages of determined weight are determined such as the following formulation: 
$O_{i}^{3}=\frac{W_{i}}{\sum W_{i}}$

Then in the next layer, the average weight values are multiple to the related function such as below:

$O_{i}^{4}=\overline{W_{l}} f_{i}=\bar{W}_{l}\left(m_{i} X_{1}+n_{i} X_{2}+r_{i}\right)$

Where, $\mathrm{m}, \mathrm{n}$, and $\mathrm{r}$ represent the resulting indexes.

At last, the fifth layer consists of the summation of previous layer outputs:

$O_{i}^{5}=Y=\sum_{i} \overline{W_{l}} f_{i}=\overline{W_{1}} f_{1}+\overline{W_{2}} f_{2}=\frac{\sum W_{i} f_{i}}{\sum W_{i}}$

\subsection{Particle swarm optimization (PSO)}

The combination of random probability distribution approach and generation of the population constructed the particle swarm optimization algorithm. Eberhart et al. introduced the PSO algorithm that comes from the social behavior of birds and developed it to solve the nonlinear function optimization problems[63]. This strategy has special similarities with other optimization approach such as genetic algorithm which is constructed base on random solution population. Each particle can be known as a probable solution of problem. A random population of particle created in search space to relate in optimum system. $\mathrm{P}_{\text {best }}$ is known as the best solution which can obtained from this strategy for a particle. Also $g_{\text {best }}$ represents the global best solution determined by swarm. The particle move in the space by time iterations and the next iteration velocity is determined by using $g_{\text {best }}, \mathrm{P}_{\text {best }}$ and current velocity[64]. The $\mathrm{P}^{\prime}$ th particle can be determined as follow:

$X_{p d}^{i t e r+1}=X_{p d}^{i t e r}+V_{p d}^{i t e r+1}$

The particle velocity is updated by the following expression: 
$v_{i d}(t+1)=w v_{i d}(t)+c_{1} r_{1}\left(p_{\text {best }, i d}(t)-X_{i i d}(t)\right)+c_{2} r_{2}\left(g_{b e s t, d}(t)-X_{i d}(t)\right)$

$\mathrm{w}, \mathrm{c}$, and $\mathrm{r}$ are inertia weight, learning rate and random number respectively[65-69].

\section{Results and discussion}

In the present study, the determined structure of MLP-ANN algorithm utilizes log-sigmoid and linear activation functions the hidden and output layers respectively. By utilization of trial and error, the optimum number of neurons in hidden layers is determined as 7 to reach the best structure of MLP-ANN algorithm. The performance of Levenberg Marquardt training of MLP-ANN algorithm based on the mean square error is shown in Figure 2. In the RBF-ANN algorithm, the radial basis function $(\mathrm{RBF})$ is utilized for hidden layers. According to information in the literature, the hidden layer neurons for RBF-ANN can be supposed one-tenth of training data points. The training process of RBF-ANN algorithm base on MSE has been reported in Figure 3. In this work, particle swarm optimization approach is applied to train the best structure of ANFIS algorithm. Figure 4 demonstrates the gained root mean squared error (RMSE) of estimated and experimental acid solubility values in training step. The optimum structure of ANFIS can be recognized by the RMSE value of 0.003 after 1000 of iteration steps. Trained membership functions of proposed ANFIS model are also shown in Figure 5 for each cluster. 


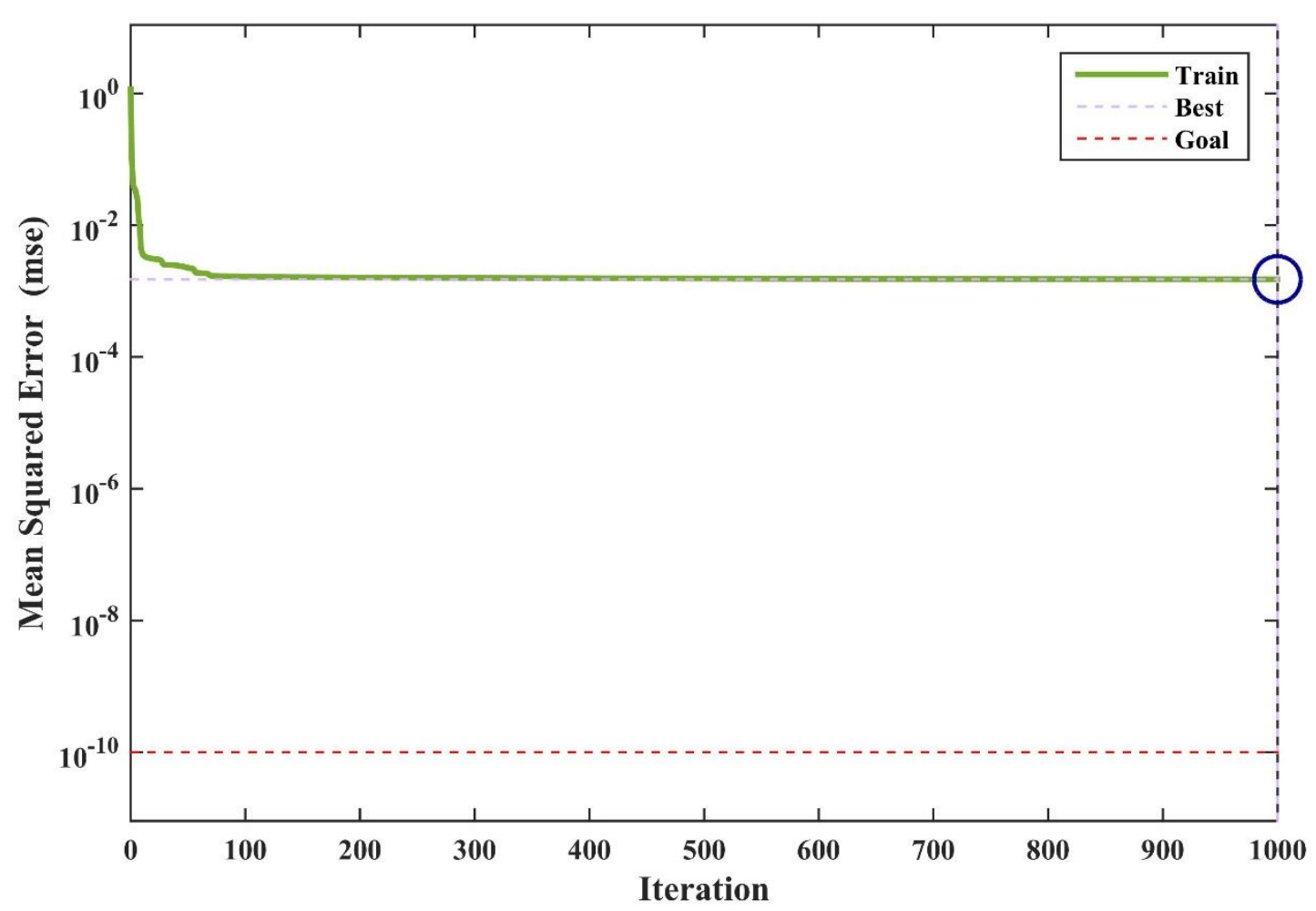

Figure 2: Trained MLP-ANN model by Levenberg Marquardt algorithm

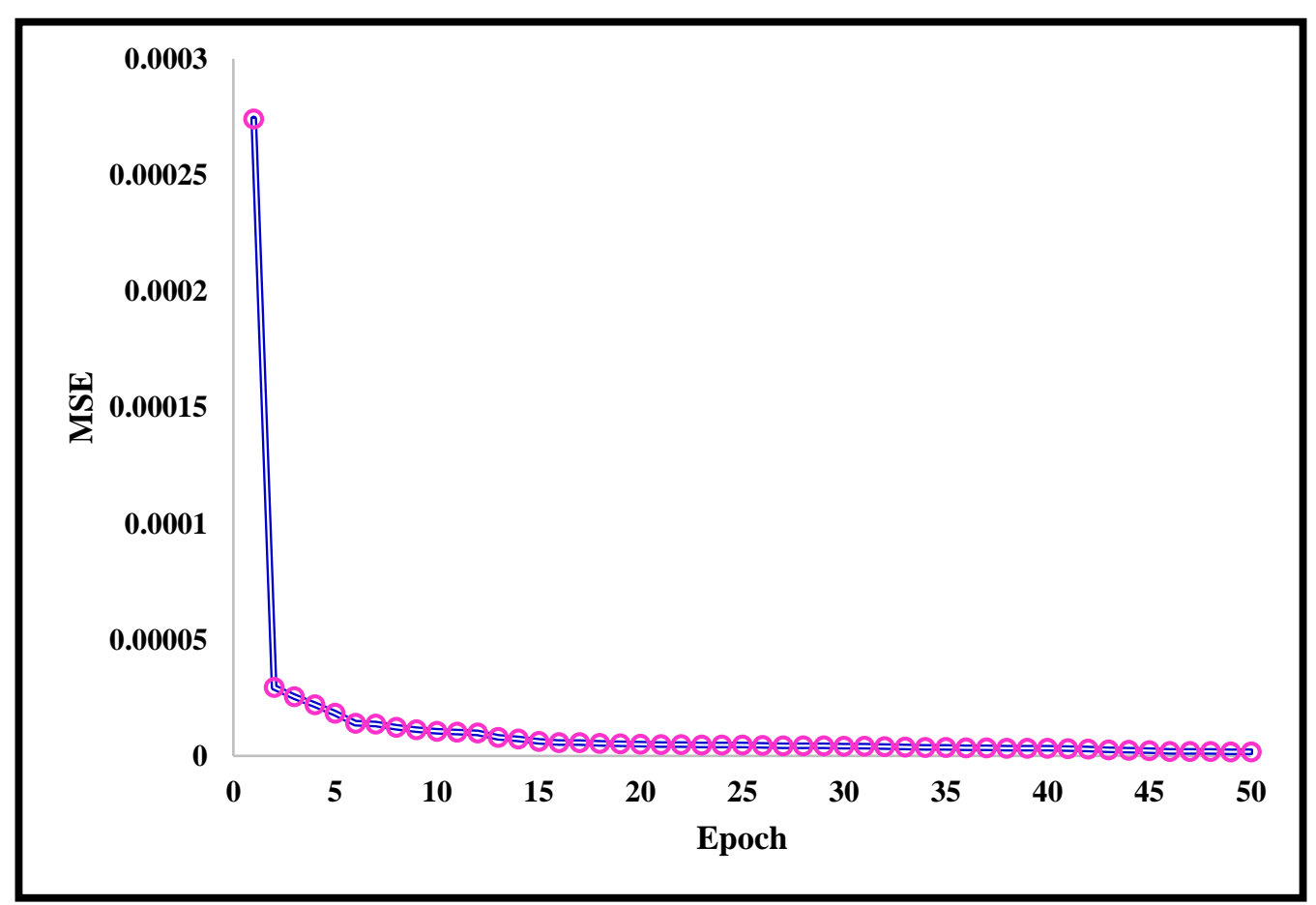

Figure 3: Trained RBF-ANN approach by Levenberg Marquardt algorithm 


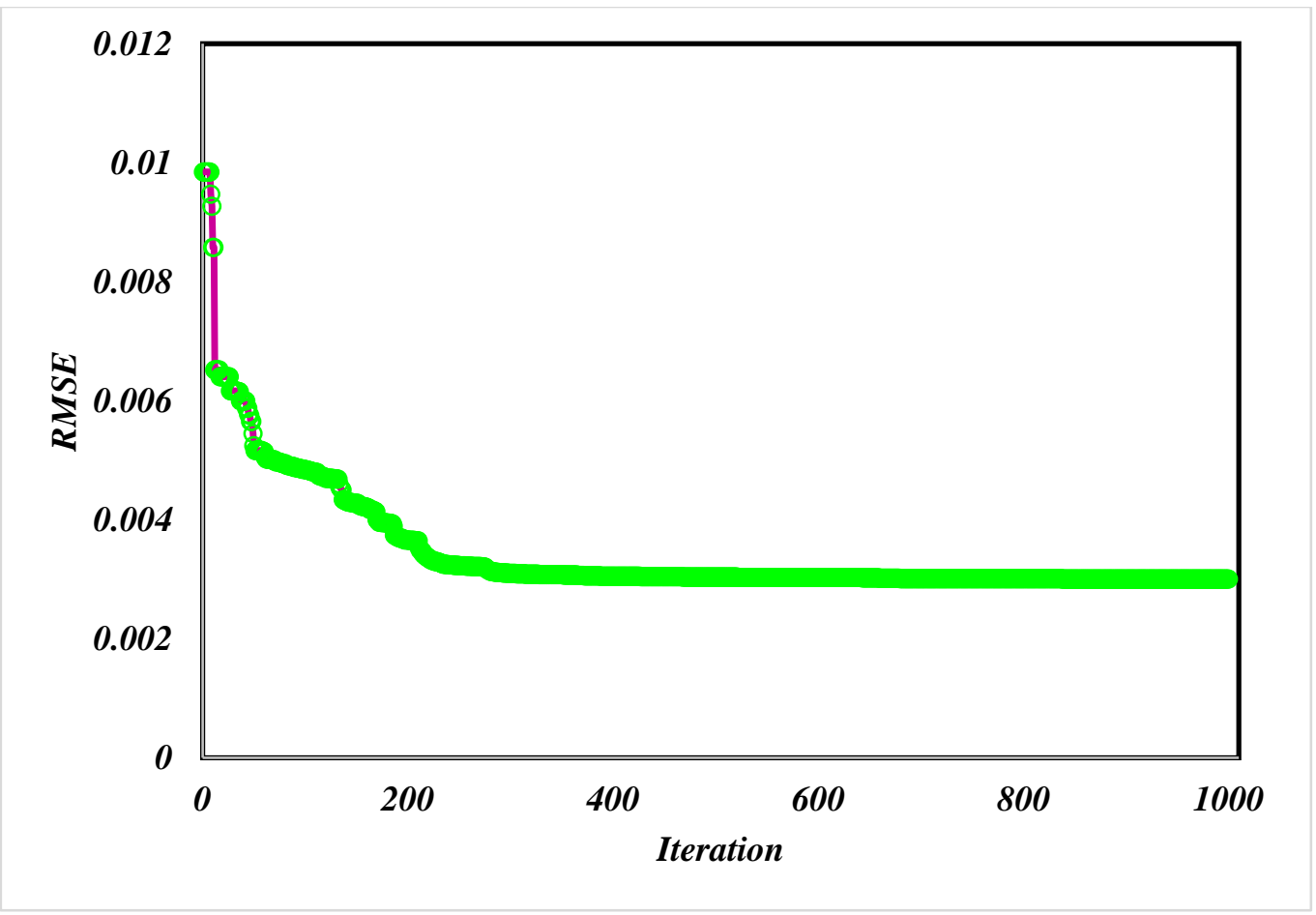

Figure 4: Performance of trained ANFIS model 

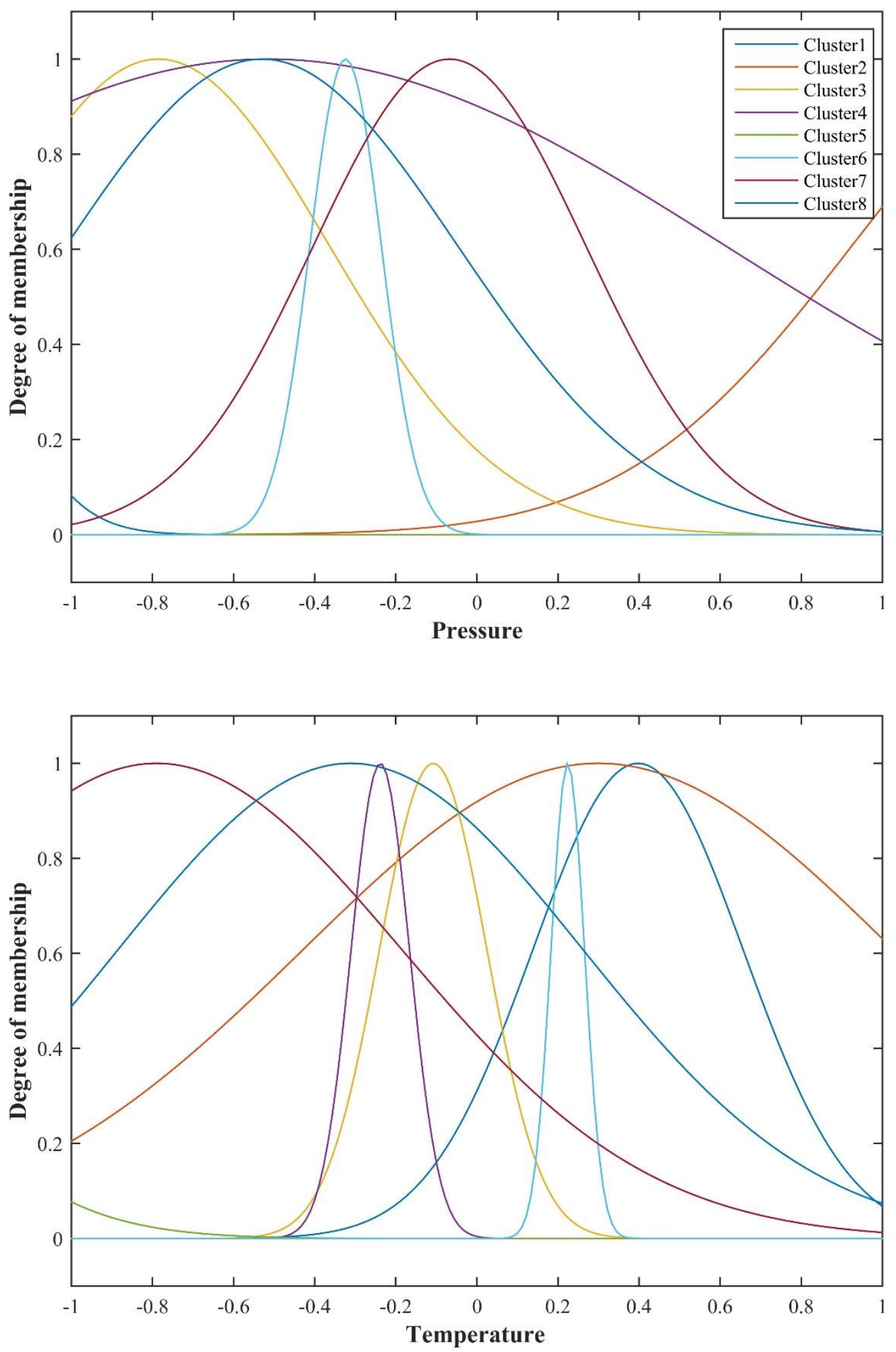

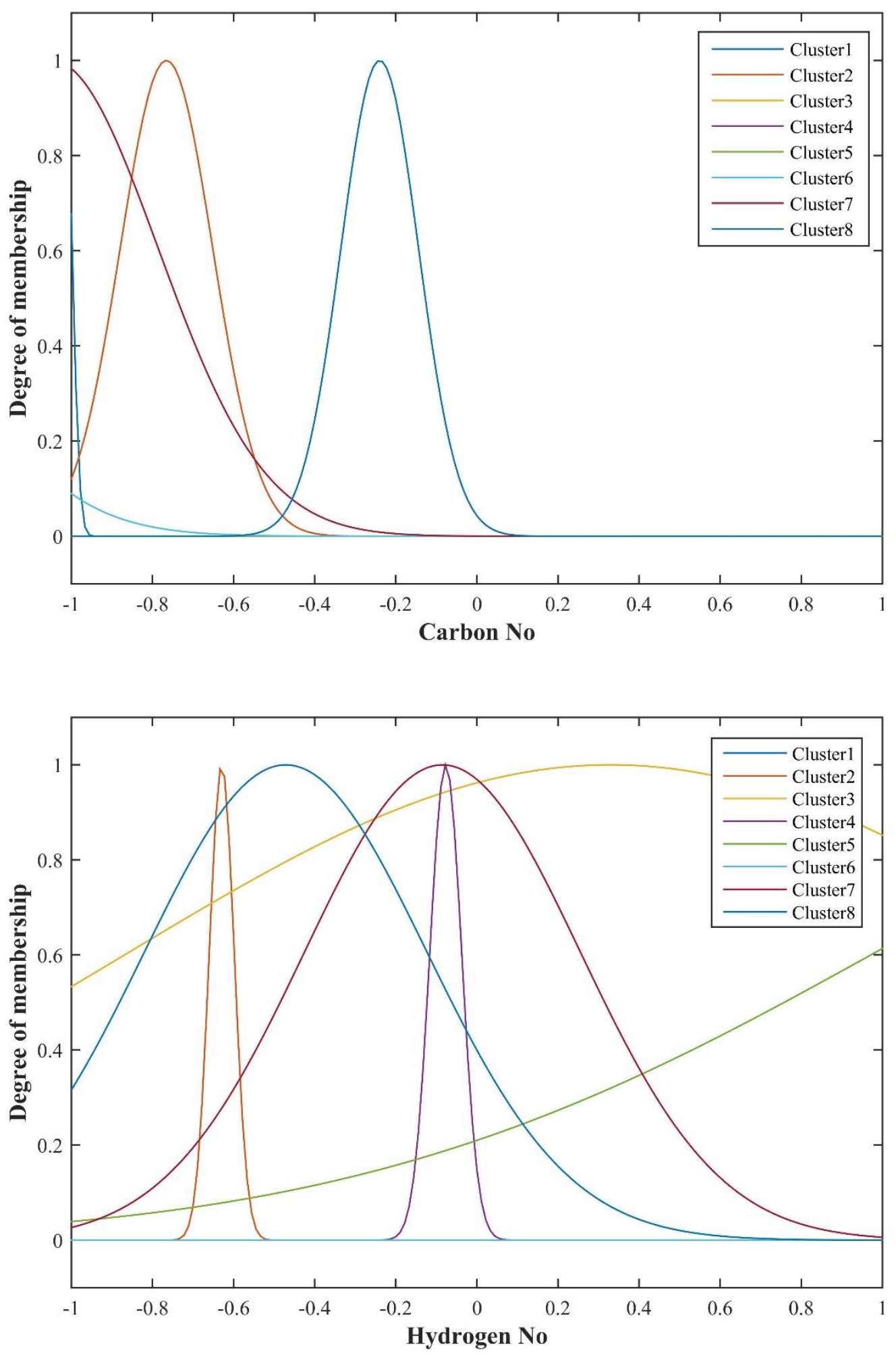

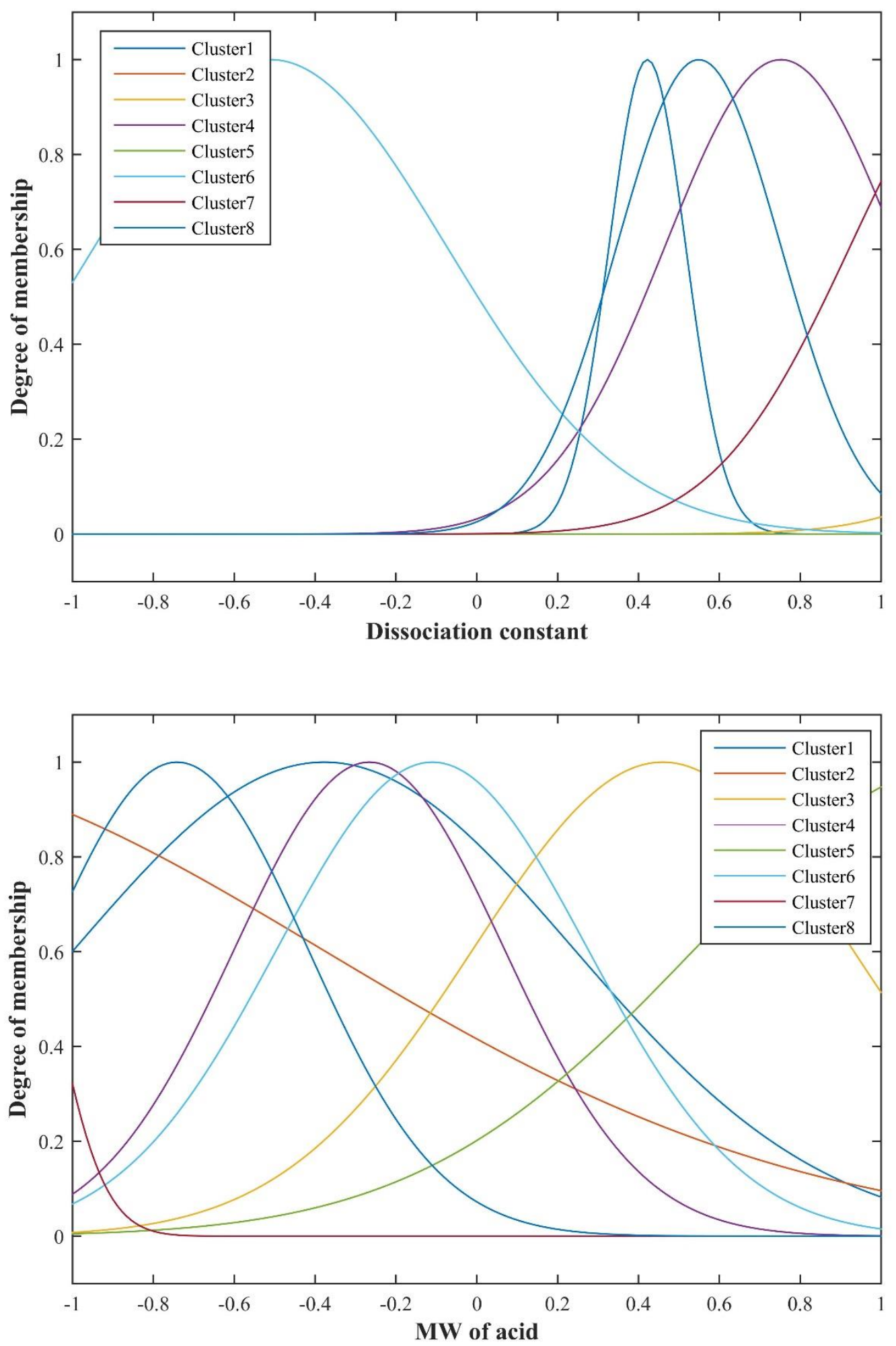

Figure 5: Trained membership function parameters 
The RBF kernel function due to its high degree of performance is utilized to construct the LSSVM algorithm. The LSSVM algorithm has two tuning parameters, $\sigma^{2}$ and $\curlyvee$ which are determined by utilizing PSO algorithm. The schematic demonstration of LSSVM algorithm is depicted in Figure 6. The details of predicting models are summarized in Table $\mathbf{1}$.

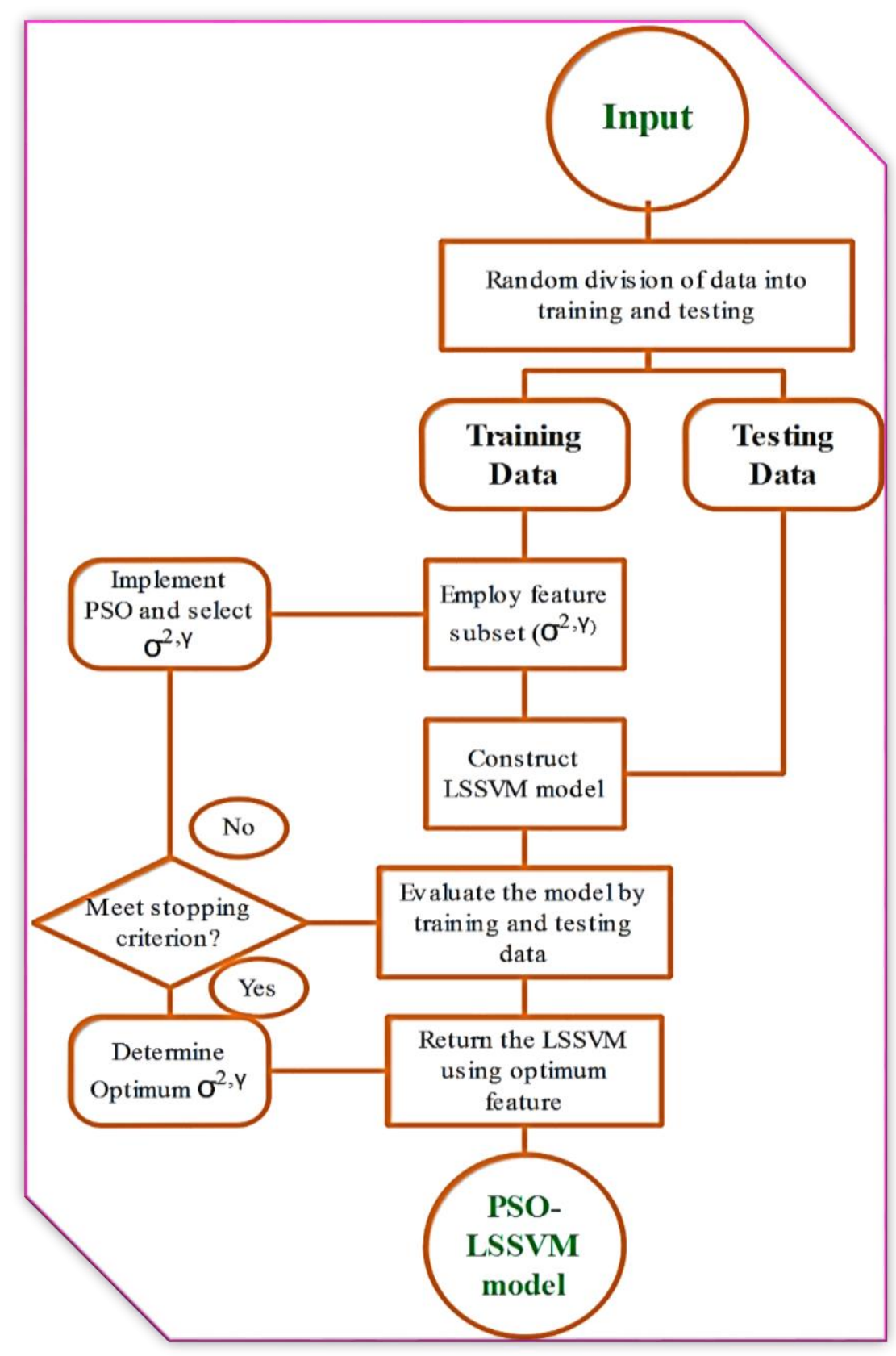

Figure 6: Schematic demonstration of trained LSSVM algorithm 
Table 1: Details of proposed models

\begin{tabular}{|c|c|c|c|}
\hline Type & comment/value & Type & comment/value \\
\hline \multicolumn{2}{|l|}{ LSSVM } & \multicolumn{2}{|l|}{ ANFIS } \\
\hline Kernel function & RBF & Membership function & Gaussian \\
\hline$\sigma^{2}$ & 0.80321 & $\begin{array}{l}\text { No. of membership function } \\
\text { parameters }\end{array}$ & 112 \\
\hline$\curlyvee$ & 12893.2264 & No. of clusters & 8 \\
\hline $\begin{array}{l}\text { Number of data utilized for } \\
\text { training }\end{array}$ & 141 & Number of data utilized for training & 141 \\
\hline $\begin{array}{l}\text { Number of data utilized for } \\
\text { testing }\end{array}$ & 47 & Number of data utilized for testing & 47 \\
\hline Population size & 85 & Population size & 50 \\
\hline Iteration & 1000 & Iteration & 1000 \\
\hline C1 & 1 & $\mathrm{C} 1$ & 1 \\
\hline C2 & 2 & $\mathrm{C} 2$ & 2 \\
\hline \multicolumn{2}{|l|}{ MLP-ANN } & \multicolumn{2}{|l|}{ MLP-ANN } \\
\hline No. input neuron layer & 6 & No. input neuron layer & 6 \\
\hline No. hidden neuron layer & 8 & No. hidden neuron layer & 50 \\
\hline No. output neuron layer & 1 & No. output neuron layer & 1 \\
\hline $\begin{array}{l}\text { Hidden layer activation } \\
\text { function }\end{array}$ & Sigmoid & Hidden layer activation function & $\mathrm{RBF}$ \\
\hline $\begin{array}{ll}\text { output layer activation } \\
\text { function }\end{array}$ & linear & output layer activation function & linear \\
\hline $\begin{array}{l}\text { Number of data utilized for } \\
\text { training }\end{array}$ & 141 & Number of data utilized for training & 141 \\
\hline $\begin{array}{l}\text { Number of data utilized for } \\
\text { testing }\end{array}$ & 47 & Number of data utilized for testing & 47 \\
\hline Number of max iteration & 1500 & Number of max iteration & 50 \\
\hline
\end{tabular}

In order to show the performance of proposed models in prediction of solubility of different acids, regression plots of RBF-ANN, MLP-ANN, ANFIS and LSSVM algorithms are depicted in Figure 7 to compare the determined and actual solubility values. Based on these plots, the surprising fits for the predicting algorithms are obtained. Also, the predicted acid solubility data for proposed models are demonstrated along with the corresponding actual acid solubility values in Figure S1. It can be observed that the model's output solubility values have excellent agreement with actual solubility values. Another graphical evaluation method is a demonstration of relative error between predicted and experimental acid solubility in supercritical carbon dioxide. Figure $\mathbf{S} 2$ shows the 
percentage of absolute error for the different predicting algorithm, which expresses the acceptable degree of accuracy in prediction of acid solubility.
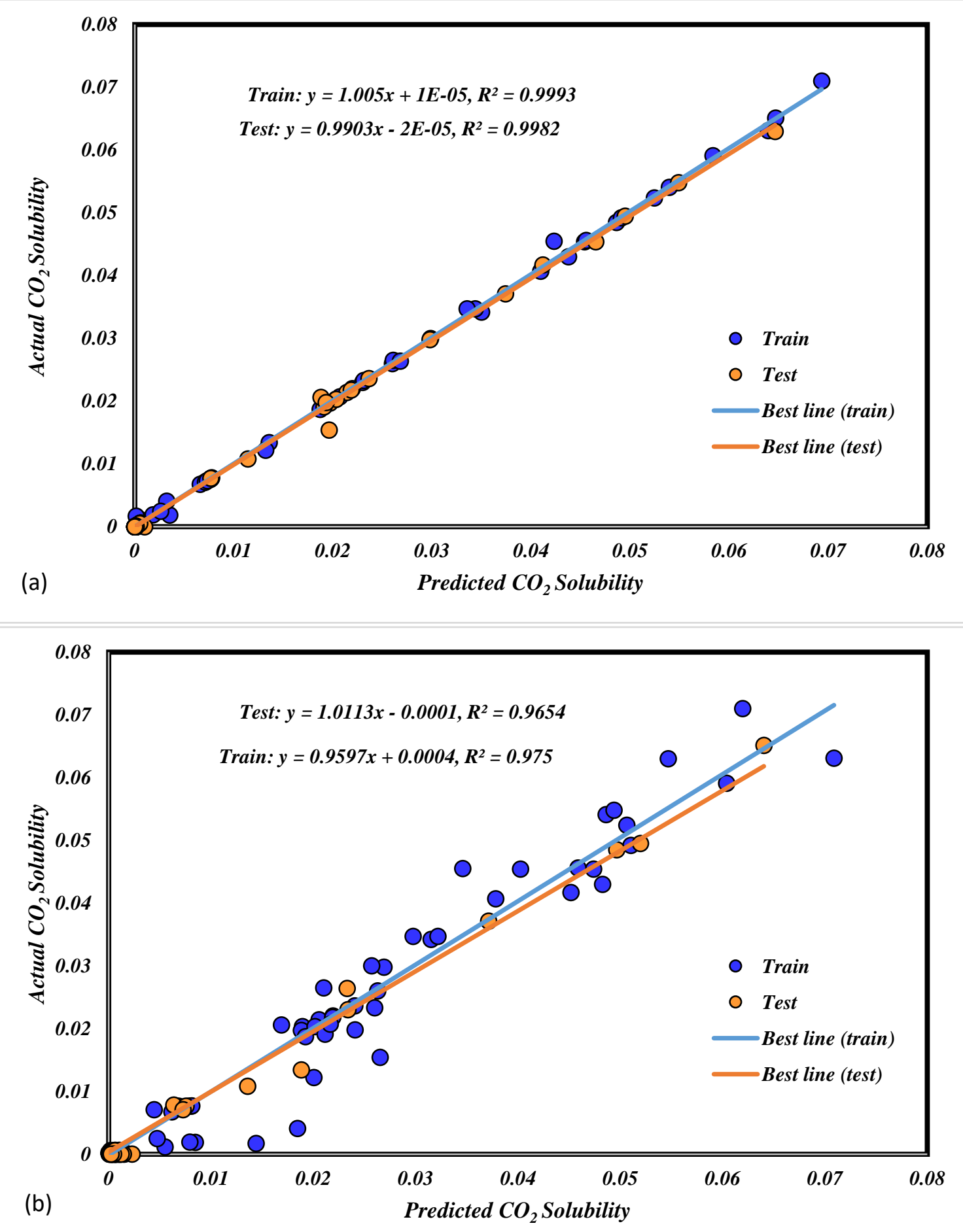

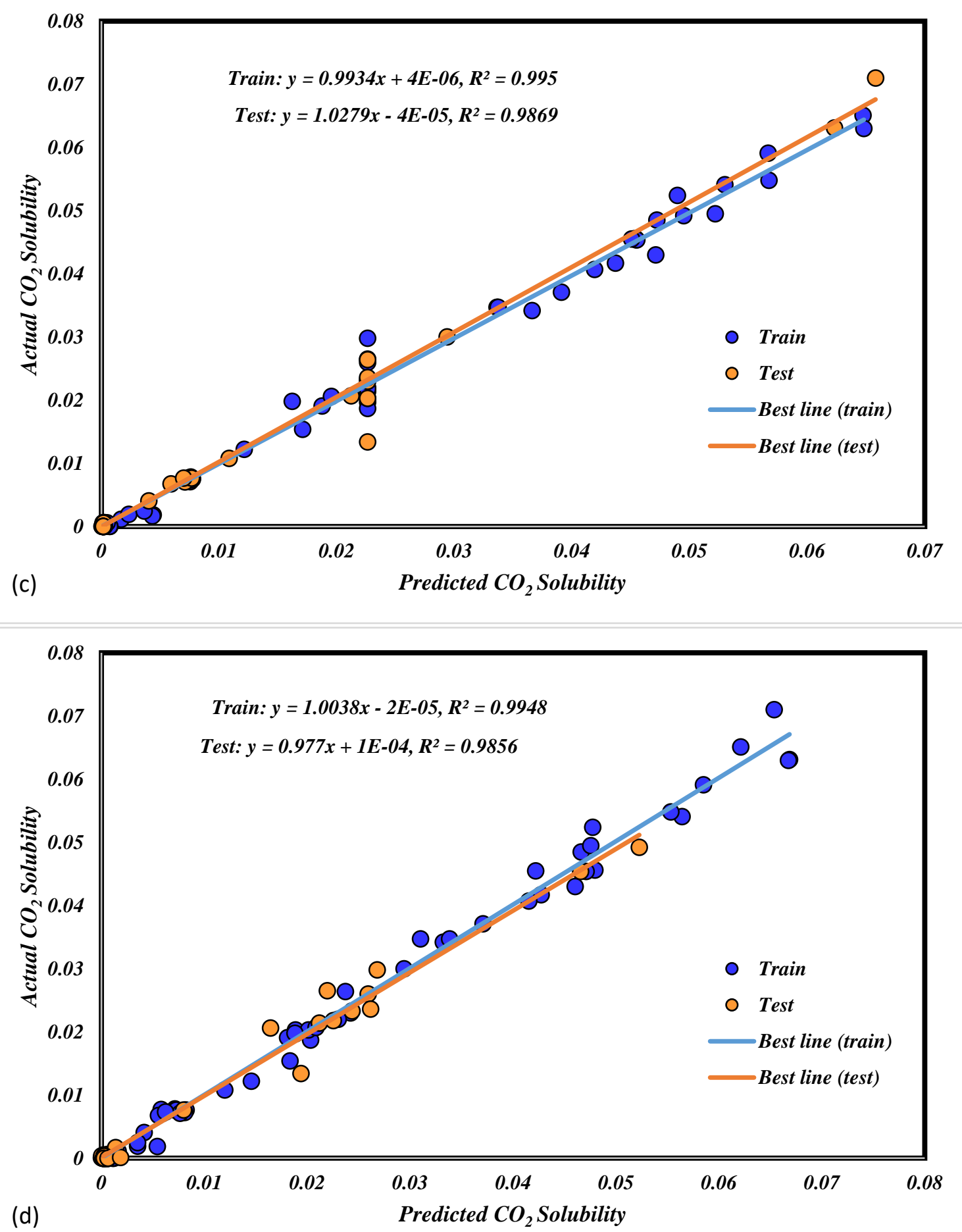

Figure 7: Regression plots obtained for different models 


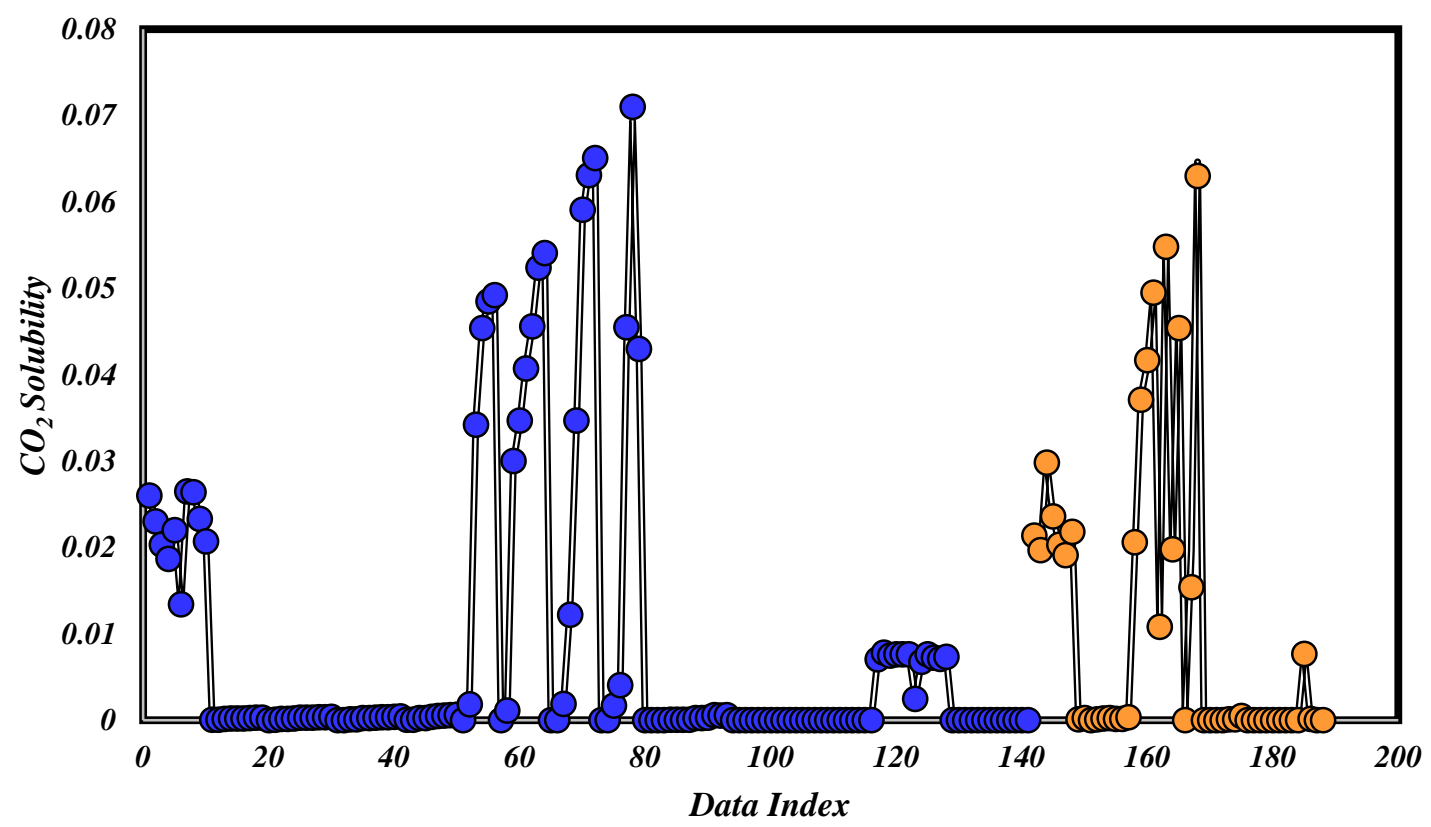

○ Train Exp. $\quad$ O Test Exp. $\quad$ Train LSSVM $\rightleftharpoons$ Test LSSVM

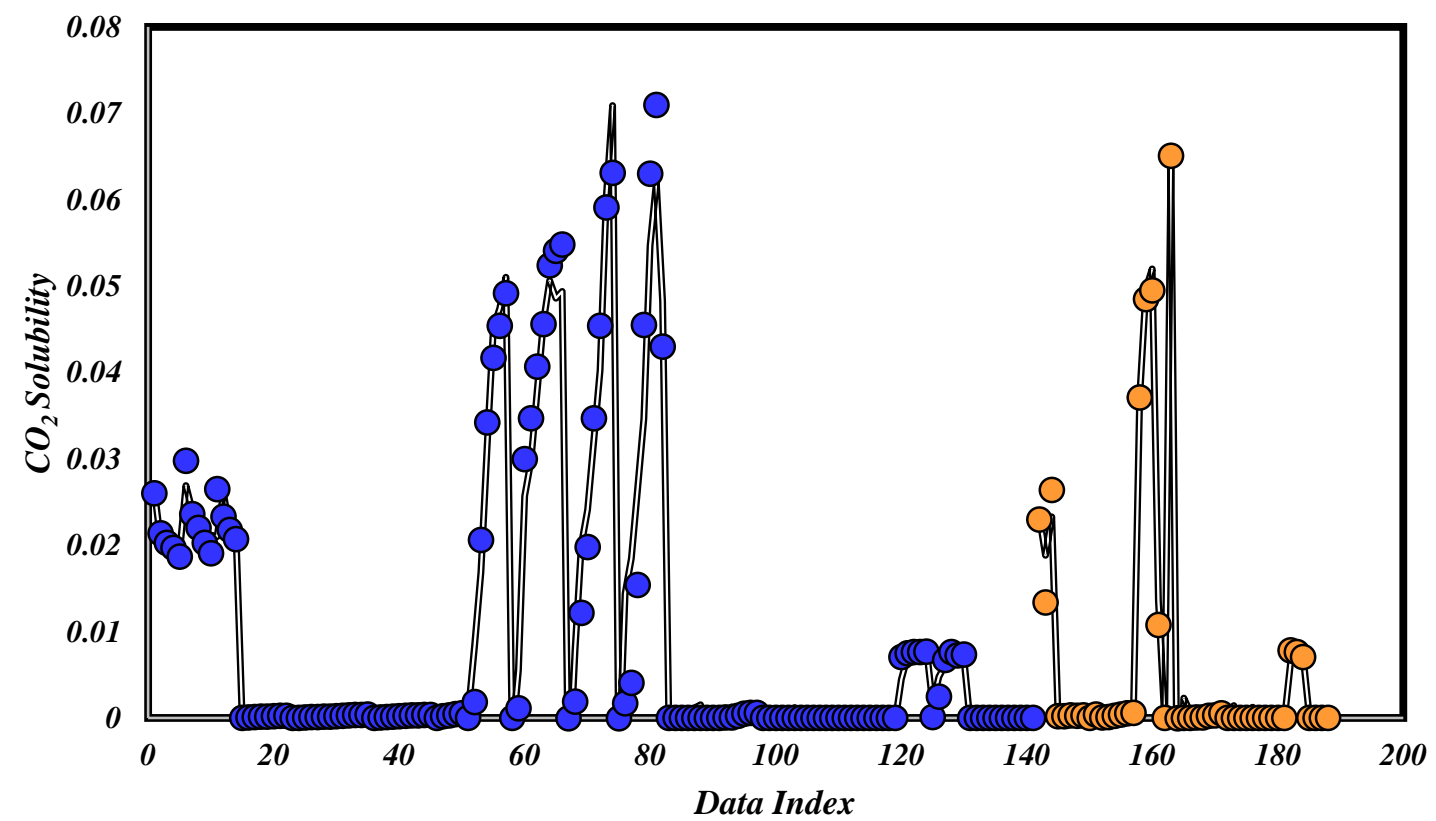

○ Train Exp. O Test Exp. $\quad$ Train ANFIS $\rightleftharpoons$ Test ANFIS 


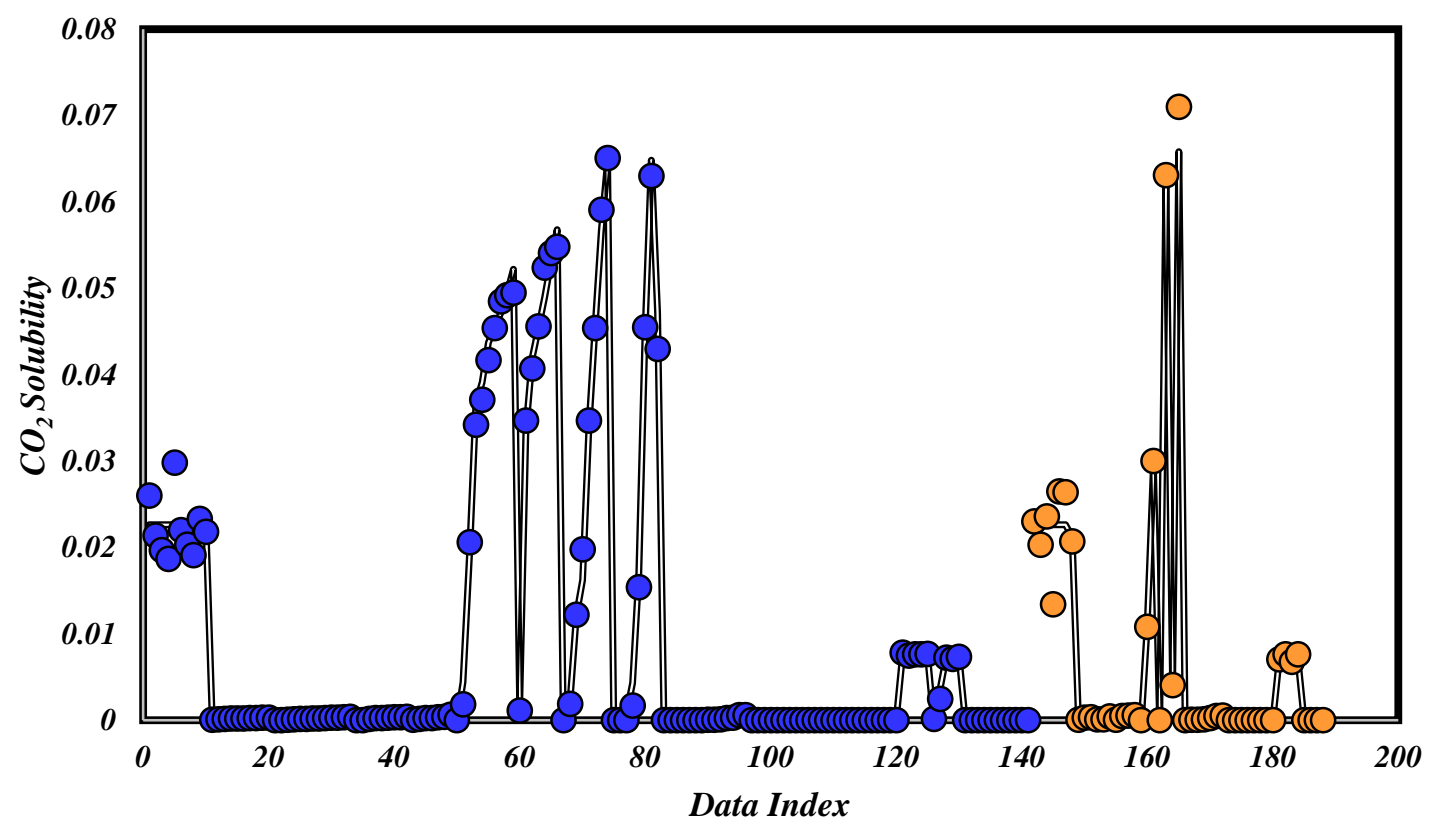

○ Train Exp. O Test Exp. $\quad$ Train MLP-ANN $\rightleftharpoons$ Test MLP-ANN

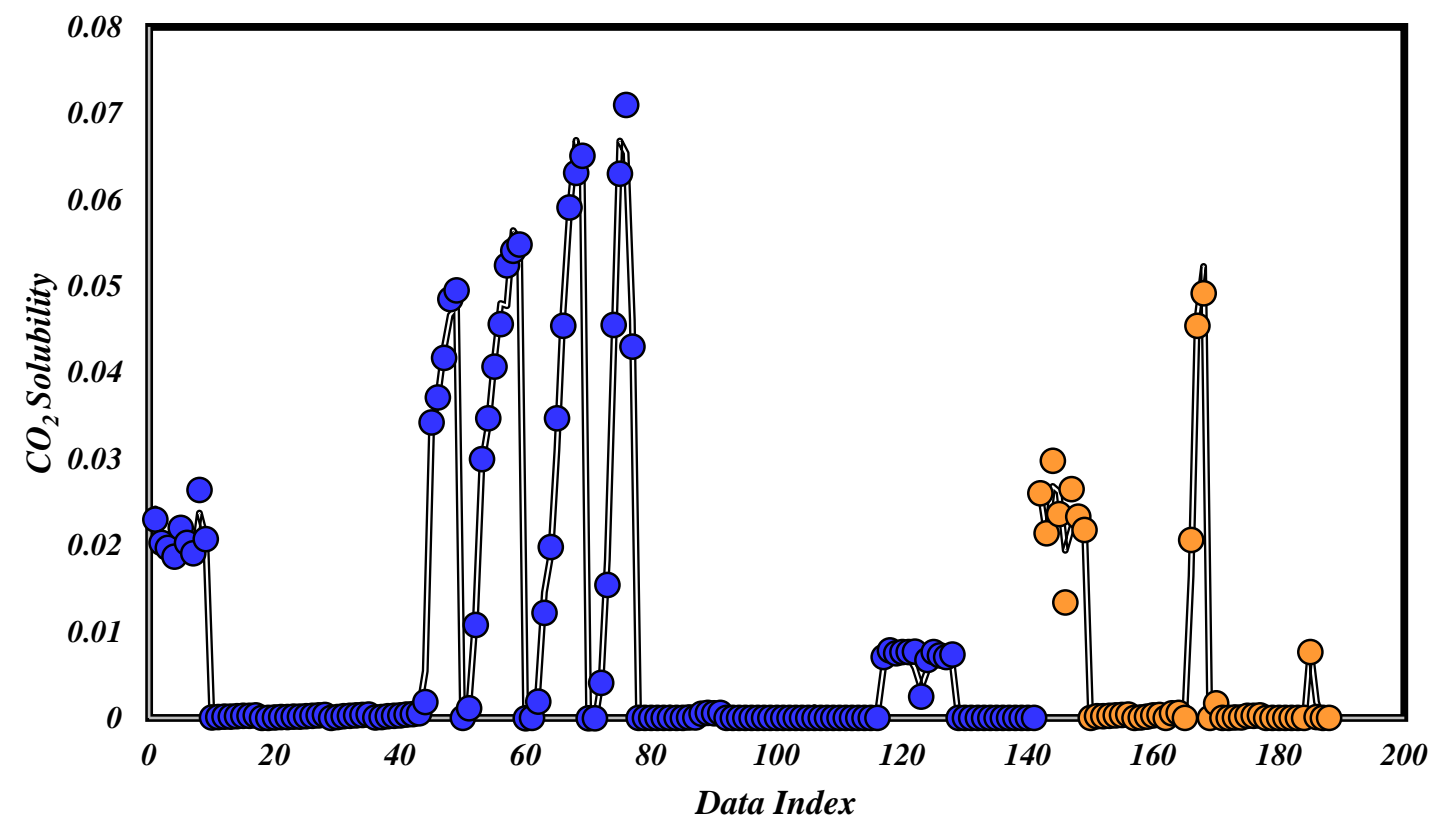

- Train Exp. O Test Exp. $\quad$ Train RBF-ANN $\rightleftharpoons$ Test RBF-ANN

Figure S1: Experimental and predicted solubility of $\mathrm{CO}_{2}$ by the proposed models 

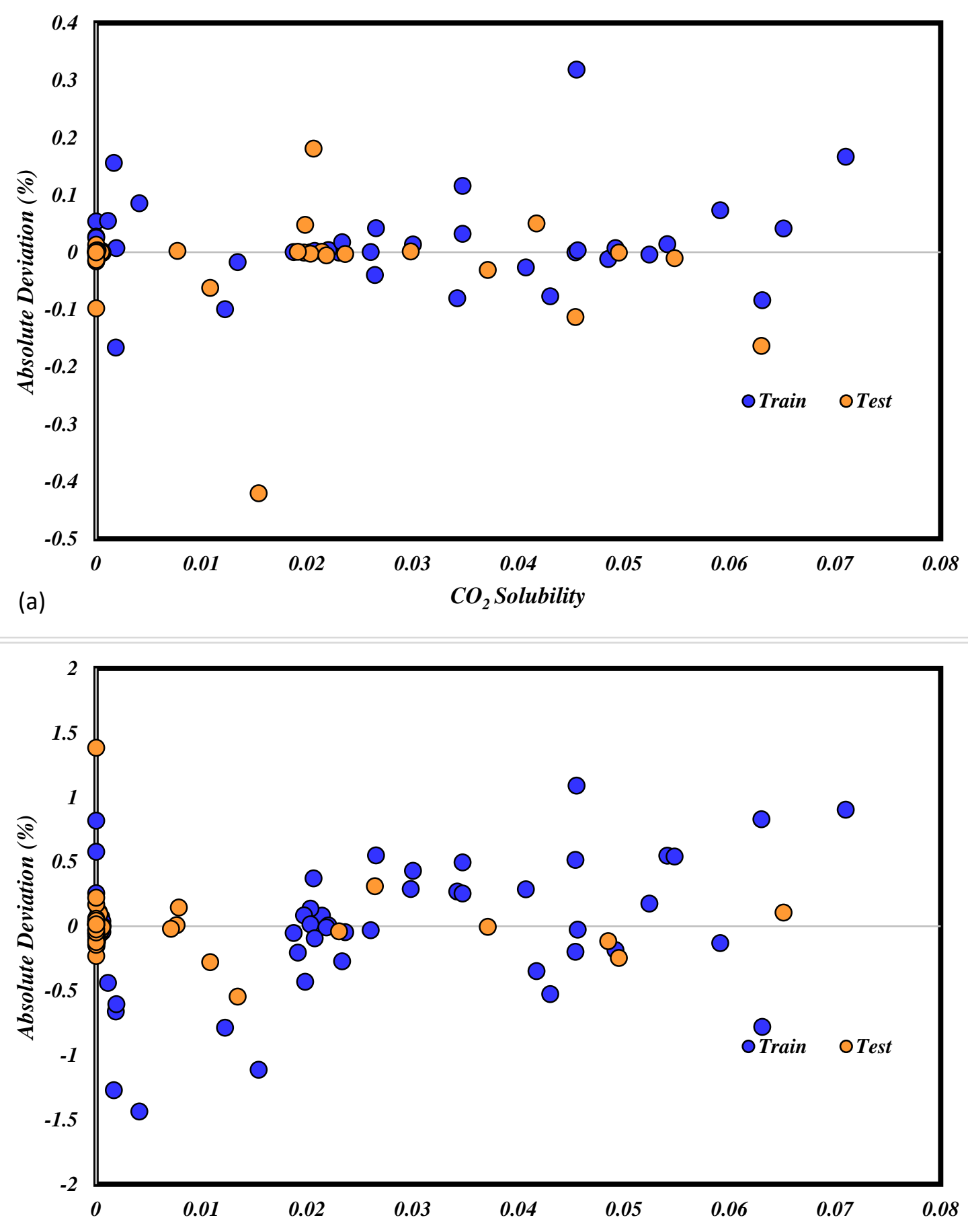

(b)

$\mathrm{CO}_{2}$ Solubility 

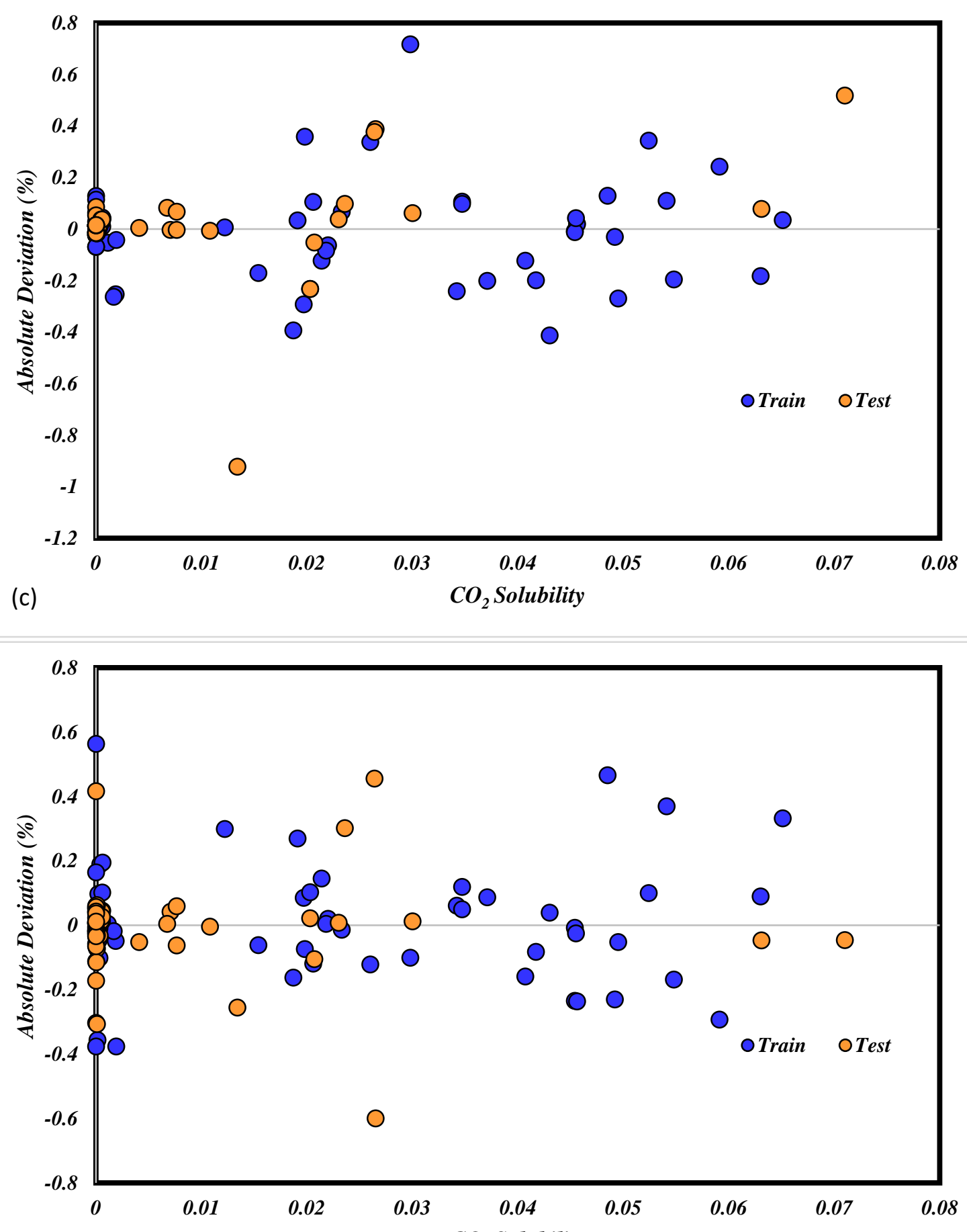

(d)

$\mathrm{CO}_{2}$ Solubility

Figure S2: Absolut deviation plots for (a) LSSVM, (b) ANFIS, (c) MLP-ANN, and (d) RBF-ANN 
Furthermore, in order to clarify the performance of predicting algorithms, the statistical analysis is required so the coefficients of determination $\left(\mathrm{R}^{2}\right)$, average absolute deviation (AAD), Mean squared errors (MSEs) and Standard deviations (STDs) are determined such as following:

$\mathrm{R}^{2}=1-\frac{\sum_{\mathrm{i}=1}^{\mathrm{N}}\left(\mathrm{X}_{\mathrm{i}}^{\text {actual }}-\mathrm{X}_{\mathrm{i}}^{\text {predicted }}\right)^{2}}{\sum_{\mathrm{i}=1}^{\mathrm{N}}\left(\mathrm{X}_{\mathrm{i}}^{\text {actual }}-\overline{\mathrm{X}^{\text {actual }}}\right)^{2}}$

$A A D=\frac{1}{N} \sum_{i=1}^{N}\left|X_{i}^{\text {predicted }}-X_{i}^{\text {actual }}\right|$

$M S E=\frac{1}{N} \sum_{i=1}^{N}\left(X_{i}^{\text {actual }}-X_{i}^{\text {predicted }}\right)^{2}$

Eq. (20)

$S T D_{\text {error }}=\left(\frac{1}{N-1} \sum_{i=1}^{N}(\text { error }-\overline{\text { error }})\right)^{0.5}$

The $\mathrm{R}^{2}, \mathrm{AD}, \mathrm{MSE}$ and STD values of different algorithms are summarized in Table 2. According to these results, the LSSVM model has the greatest ability in forecasting acid solubility.

Table 2: Statistical analyses of models

\begin{tabular}{llccccc}
\hline Model & Set & MSE & RMSE & $\mathbf{R}^{\mathbf{2}}$ & STD & AAD (\%) \\
\hline LSSVM & Train & $\begin{array}{c}5.72159 \mathrm{E}- \\
07\end{array}$ & 0.000756 & 0.998 & 0.0007 & 0.0269 \\
& Test & $1.7978 \mathrm{E}-07$ & 0.000424 & 0.999 & 0.0004 & 0.0149 \\
& Total & $\begin{array}{c}2.77875 \mathrm{E}- \\
07\end{array}$ & 0.000527 & 0.999 & 0.0005 & 0.0179 \\
& Train & $\begin{array}{c}5.79633 \mathrm{E}- \\
06\end{array}$ & 0.002408 & 0.975 & 0.0022 & 0.1093 \\
ANFIS & Test & $\begin{array}{c}1.00976 \mathrm{E}- \\
05\end{array}$ & 0.003178 & 0.965 & 0.0027 & 0.1677 \\
& Total & $\begin{array}{c}9.02227 \mathrm{E}- \\
06\end{array}$ & 0.003004 & 0.967 & 0.0026 & 0.1531 \\
& Train & $\begin{array}{c}3.23782 \mathrm{E}- \\
06\end{array}$ & 0.001799 & 0.987 & 0.0017 & 0.0756 \\
MLP- & Test & $\begin{array}{c}1.44839 \mathrm{E}- \\
06\end{array}$ & 0.001203 & 0.995 & 0.0010 & 0.0600 \\
ANN & & & & & \\
\hline
\end{tabular}




\begin{tabular}{lcccccc}
\hline & Total & $\begin{array}{c}1.89575 \mathrm{E}- \\
06\end{array}$ & 0.001377 & 0.993 & 0.0012 & 0.0639 \\
RBF-ANN & Train & $\begin{array}{c}2.33037 \mathrm{E}- \\
06\end{array}$ & 0.001527 & 0.986 & 0.0013 & 0.0827 \\
& Test & $\begin{array}{c}1.61993 \mathrm{E}- \\
06\end{array}$ & 0.001273 & 0.995 & 0.0010 & 0.0779 \\
& Total & $\begin{array}{c}1.79754 \mathrm{E}- \\
06\end{array}$ & 0.001341 & 0.993 & 0.0011 & 0.0791 \\
& & & & & \\
\hline
\end{tabular}

In addition to previous statistical indexes, there is another statistical approach to evaluate the reliability and accuracy of predicting algorithm, which called Leverage method. The mentioned approach consists of some statistical concepts such as model residuals, Hat matrix and Williams plot which are used for detection of suspected and outlier data. There is more description of Leverage method in the literature [70-72].In this method, the residuals are estimated and inputs are utilized to build a matrix called Hat matrix such as follow:

$H=X\left(X^{T} X\right)^{-1} X^{T}$

Where $\mathrm{X}$ is the $\mathrm{m} \times \mathrm{n}$ matrix which $\mathrm{n}$ and $\mathrm{m}$ are the numbers of model parameters and samples respectively.

Figure 8 illustrates the William plot for the proposed models. As shown in this figure, the most of data points to place in the range of leverage limit and lower and higher residuals of -3 to 3 . The leverage limit is formulated such as following:

$H^{*}=3(n+1) / m$ Eq. (23) 

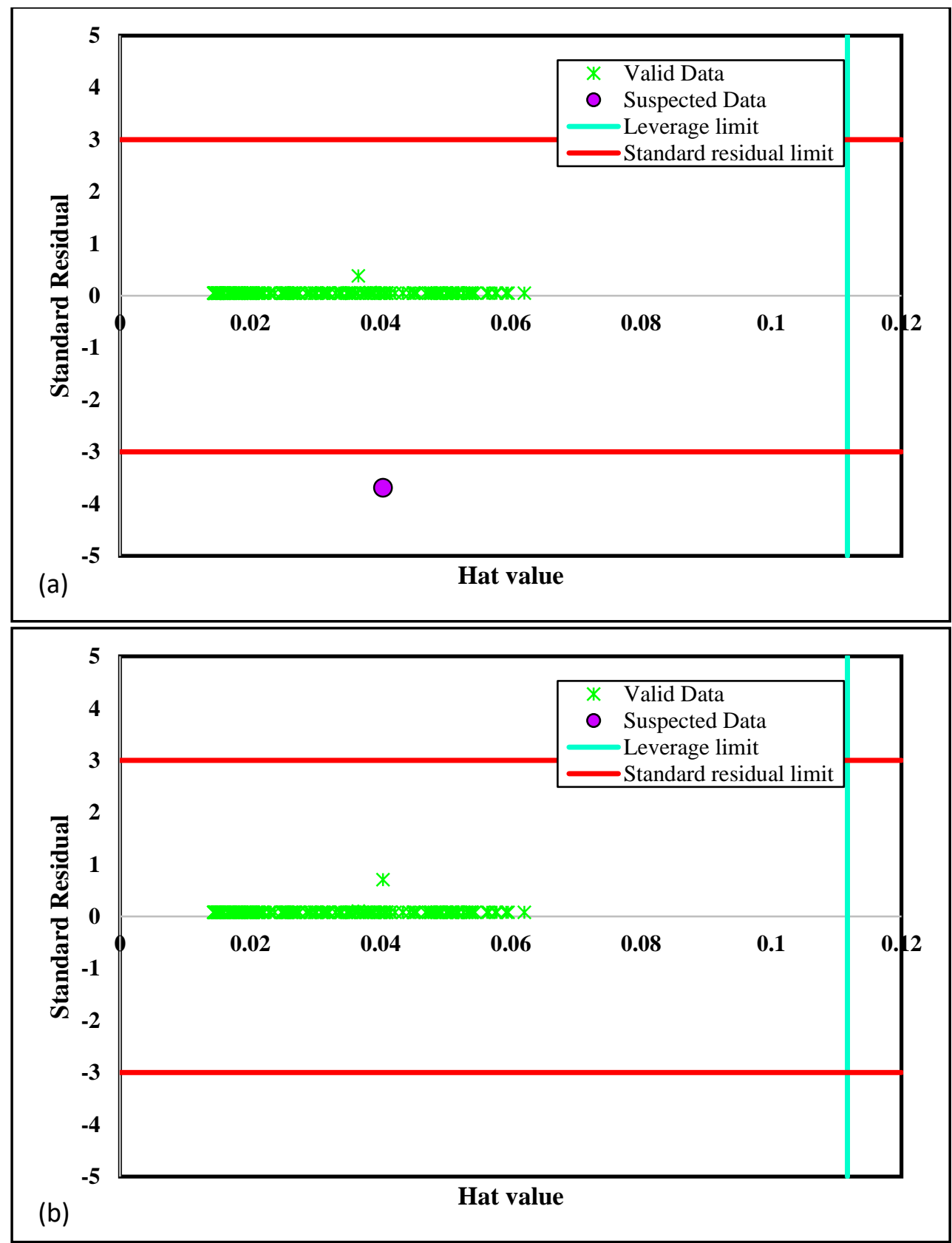

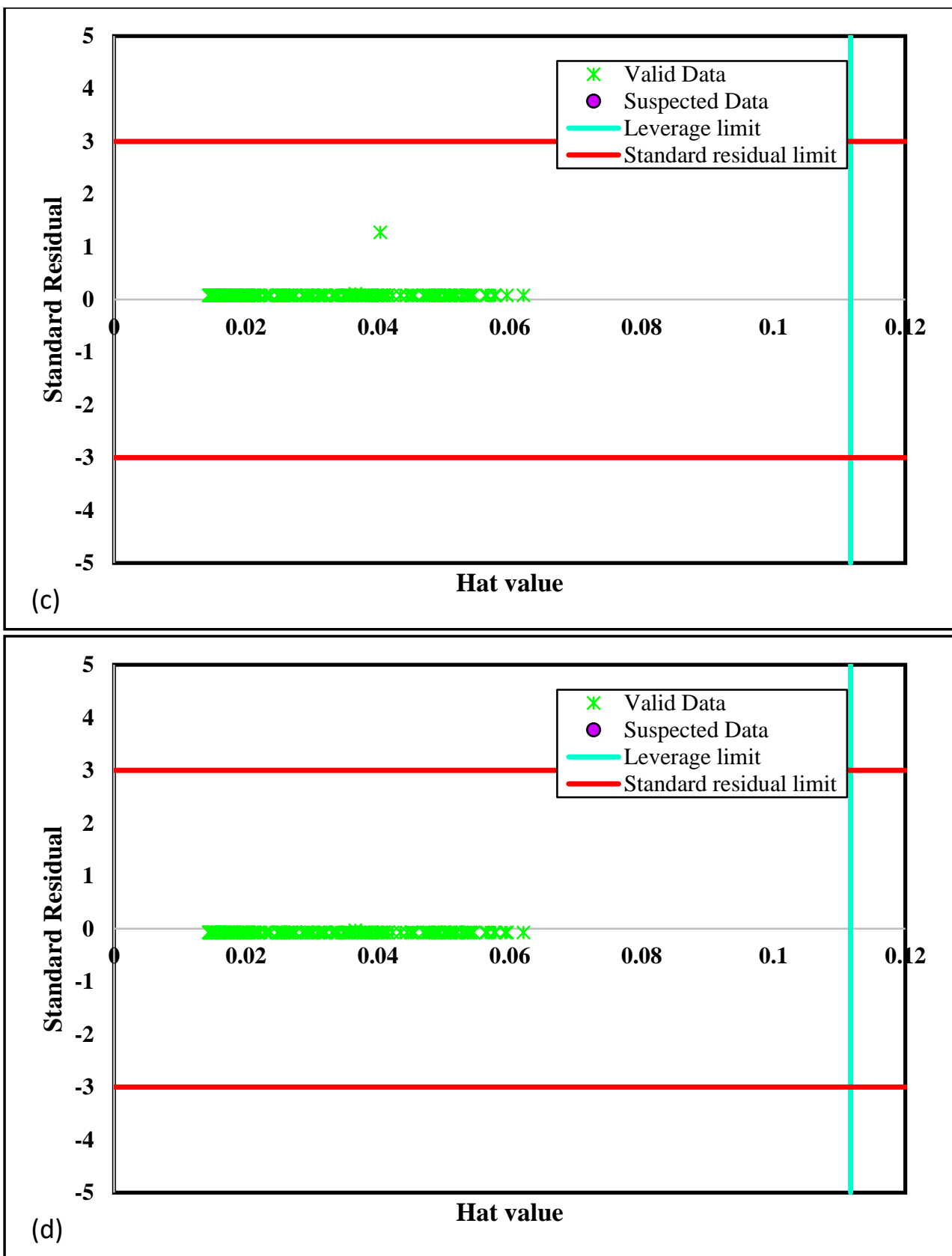

Figure 8: Absolute deviation plots for (a) LSSVM, (b) ANFIS, (c) MLP-ANN, and (d) RBF-ANN

Another method to investigate the validity of the models is a parametric analysis of solubility. To this end, the Relevancy index is introduced to investigate the impact of inputs on acid solubility. The Relevancy index is determined such as following[70]:

$$
r=\frac{\sum_{i=1}^{n}\left(X_{k, i}-\overline{X_{k}}\right)\left(Y_{i}-\bar{Y}\right)}{\sqrt{\sum_{i=1}^{n}\left(X_{k, i}-\overline{X_{k}}\right)^{2} \sum_{i=1}^{n}\left(Y_{i}-\bar{Y}\right)^{2}}}
$$


Which $Y_{i}, \bar{Y}, X_{k, i}$ and $\overline{X_{k}}$ are the 'i' th output, output average, kth of input and average of input. The Relevancy index absolute value represent the effectiveness of the parameters on acid solubility. As shown in Figure 9, the molecular weight of acid has the most Relevancy factor between different input parameters so this parameter is known as the most effective parameters on acid solubility in supercritical carbon dioxide.

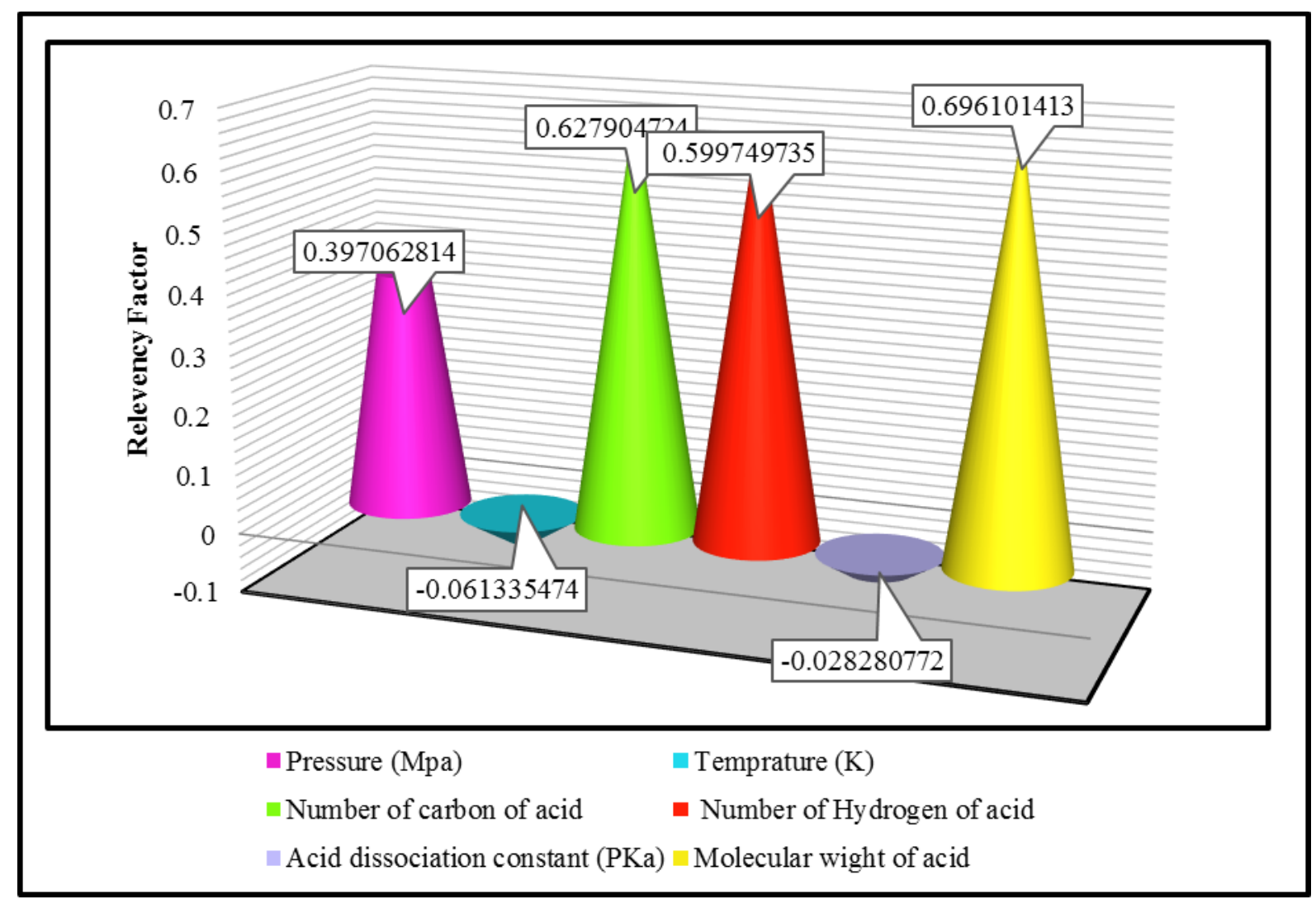

Figure 9: Sensitivity analysis of investigated variables

\section{Conclusions}

In this paper, we have applied RBF-ANN, MLP-ANN, ANFIS-PSO and LSSVM algorithms to determine the different acids solubility values in supercritical carbon dioxide in terms of pressure, temperature and different acid structure based on a reliable databank which gathered from the literature. These predicting approaches can forecast acid solubility in the wide range of operating 
conditions. To prove the aforementioned acclaim, different statistical and graphical evaluations have been performed in the previous section. According to the obtained results from comparisons, the LSSVM model has the best performance respect to the others and ANFIS algorithm has the least of accuracy in this prediction. Also, the results of sensitivity analysis identify the molecular weight of the acid parameter is the most effective factor in solubility of acids in supercritical carbon dioxide. Based on these comprehensive investigations this manuscript has great potential and ability to help the researchers in their future works. 


\section{Nomenclature}

$\begin{array}{ll}\text { ANFIS } & \text { Adaptive neuro-fuzzy inference system } \\ \text { LSSVM } & \text { Least squares support vector machine } \\ \text { RBF-ANN } & \text { Radial basis function artificial neural network } \\ \text { MLP-ANN } & \text { Multi-layer Perceptron artificial neural } \\ & \text { network } \\ \text { PSO } & \text { Particle swarm optimization } \\ \boldsymbol{\varphi}(\mathbf{x}) & \text { nonlinear function } \\ \mathbf{\omega} & \text { weight } \\ \mathbf{b} & \text { bias } \\ \mathbf{Y} & \text { regularization parameter } \\ \mathbf{e} & \text { support value } \\ \text { K } & \text { kernel function } \\ \text { Z } & \text { Gaussian parameter } \\ \boldsymbol{\sigma} & \text { Gaussian parameter } \\ \mathbf{m} & \text { One of the resulting index of ANFIS } \\ \mathbf{n} & \text { One of the resulting index of ANFIS } \\ \mathbf{r} & \text { One of the resulting index of ANFIS } \\ \text { W } & \text { inertia weight } \\ \mathbf{c} & \text { learning rate } \\ \mathbf{R}^{2} & \text { coefficient of determination } \\ \text { AAD } & \text { average absolute deviation } \\ \text { MSE } & \text { Mean squared error } \\ \text { STD } & \text { Standard deviation } \\ \text { H } & \text { Hat matrix } \\ \text { H* } & \text { The leverage limit } \\ & \end{array}$




\section{References}

[1] F.L. Celso, A. Triolo, F. Triolo, J. McClain, J. Desimone, R. Heenan, H. Amenitsch, R. Triolo, Applied Physics A 74 (2002) s1427.

[2] A. Daryasafar, N. Daryasafar, M. Madani, M.K. Meybodi, M. Joukar, Neural Computing and Applications 29 (2018) 295.

[3] H. Inomata, Y. Honma, M. Imahori, K. Arai, Fluid phase equilibria 158 (1999) 857.

[4] P. Munshi, S. Bhaduri, Current Science (00113891) 97 (2009).

[5] L. Nahar, S.D. Sarker, Natural Products Isolation, Springer, 2012, p. 43-74.

[6] H. Ohde, F. Hunt, C.M. Wai, Chemistry of materials 13 (2001) 4130.

[7] A. Stassi, R. Bettini, A. Gazzaniga, F. Giordano, A. Schiraldi, Journal of Chemical \& Engineering Data 45 (2000) 161.

[8] S. Üzer, U. Akman, Ö. Hortaçsu, The Journal of supercritical fluids 38 (2006) 119.

[9] X. Zhang, S. Heinonen, E. Levänen, Rsc Advances 4 (2014) 61137.

[10] Z. Zhao, X. Zhang, K. Zhao, P. Jiang, Y. Chen, Applied Thermal Engineering 126 (2017) 717.

[11] W. Gao, M. Abdi-khanghah, M. Ghoroqi, A. Daryasafar, M. Lavasani, The Journal of Supercritical Fluids 131 (2018) 87.

[12] A. Belghait, C. Si-Moussa, M. Laidi, S. Hanini, Comptes Rendus Chimie (2018).

[13] Z.e. Knez, D. Cör, M.a. Knez Hrnčič, Journal of Chemical \& Engineering Data (2017).

[14] C. Erkey, The Journal of Supercritical Fluids 17 (2000) 259.

[15] J. Sunarso, S. Ismadji, Journal of hazardous materials 161 (2009) 1.

[16] F. Lin, D. Liu, S. Maiti Das, N. Prempeh, Y. Hua, J. Lu, Industrial \& Engineering Chemistry Research 53 (2014) 1866.

[17] H.S. Ghaziaskar, M. Nikravesh, Fluid phase equilibria 206 (2003) 215.

[18] S. Bovard, M. Abdi, M.R.K. Nikou, A. Daryasafar, The Journal of Supercritical Fluids 119 (2017) 88.

[19] H.S. Ghaziaskar, M. Kaboudvand, The Journal of Supercritical Fluids 44 (2008) 148. 
[20] Z. Huang, Y.C. Chiew, W.-D. Lu, S. Kawi, Fluid Phase Equilibria 237 (2005) 9.

[21] K. Hintzer, M. Juergens, G.J. Kaempf, H. Kaspar, K.H. Lochhaas, A. Streiter, O. Shyshkov, T.C. Zipplies, H. Koenigsmann, Google Patents, 2016.

[22] A. Dartiguelongue, A. Leybros, A.s. Grandjean, Journal of Chemical \& Engineering Data 61 (2016) 3902.

[23] K. Hintzer, G. Löhr, A. Killich, W. Schwertfeger, Google Patents, 2004.

[24] C.A. Moody, J.A. Field, Environmental science \& technology 33 (1999) 2800.

[25] H. Hubbard, Z. Guo, K. Krebs, S. Metzger, C. Mocka, R. Pope, N. Roache, US EPA Report EPA/600/R-12/703 (2012).

[26] H.P. Richter, E.J. Dibble, Google Patents, 1983.

[27] C. Fei, J. Olsen, Environmental health perspectives 119 (2011) 573.

[28] G.S. Gurdial, N.R. Foster, Industrial \& Engineering Chemistry Research 30 (1991) 575.

[29] A.C. Kumoro, Journal of Chemical \& Engineering Data 56 (2011) 2181.

[30] M. Sahihi, H.S. Ghaziaskar, M. Hajebrahimi, Journal of Chemical \& Engineering Data 55 (2010) 2596.

[31] H.S. Ghaziaskar, S. Afsari, M. Rezayat, H. Rastegari, The Journal of Supercritical Fluids 119 (2017) 52.

[32] H. Sovova, M. Zarevucka, M. Vacek, K. Stránský, the Journal of Supercritical fluids 20 (2001) 15.

[33] D.L. Sparks, L.A. Estévez, R. Hernandez, K. Barlow, T. French, Journal of Chemical \& Engineering Data 53 (2008) 407.

[34] D.L. Sparks, R. Hernandez, L.A. Estévez, N. Meyer, T. French, Journal of Chemical \& Engineering Data 52 (2007) 1246.

[35] G.-h. Tian, J.-s. Jin, J.-j. Guo, Z.-t. Zhang, Journal of Chemical \& Engineering Data 52 (2007) 1800.

[36] D. Baş, I.H. Boyac1, Journal of food engineering 78 (2007) 836.

[37] M. Smith, Neural networks for statistical modeling. Thomson Learning, 1993.

[38] A. Baghban, M.A. Ahmadi, B.H. Shahraki, The Journal of supercritical fluids 98 (2015) 50. 
[39] A. Baghban, A. Bahadori, A.H. Mohammadi, A. Behbahaninia, International Journal of Greenhouse Gas Control 57 (2017) 143.

[40] A. Baghban, A.H. Mohammadi, M.S. Taleghani, International Journal of Greenhouse Gas Control 58 (2017) 19.

[41] A. Baghban, S. Zilabi, S. Golrokhifar, S. Habibzadeh, Petroleum Science and Technology (2018) 1.

[42] K. Chiteka, C. Enweremadu, Journal of Cleaner Production 135 (2016) 701.

[43] W. Sun, Y. Xu, Journal of Cleaner Production 112 (2016) 1282.

[44] H. Shabanpour, S. Yousefi, R.F. Saen, Journal of Cleaner Production 142 (2017) 1098.

[45] M. Abdi-Khanghah, A. Bemani, Z. Naserzadeh, Z. Zhang, Journal of CO2 Utilization 25 (2018) 108.

[46] K. Movagharnejad, B. Mehdizadeh, M. Banihashemi, M.S. Kordkheili, Energy 36 (2011) 3979.

[47] V. Vapnik, Statistical learning theory. 1998. Wiley, New York, 1998.

[48] J.A. Suykens, J. Vandewalle, Neural processing letters 9 (1999) 293.

[49] J.A. Suykens, J. Vandewalle, B. De Moor, Neural networks 14 (2001) 23.

[50] C. Cortes, V. Vapnik, Machine learning 20 (1995) 273.

[51] Y. Wang, S. Zhang, Z. Liu, H. Li, L. Wang, Marine Biotechnology 7 (2005) 279.

[52] A. Baghban, M.A. Ahmadi, B. Pouladi, B. Amanna, The Journal of Supercritical Fluids 101 (2015) 184.

[53] A. Baylar, D. Hanbay, M. Batan, Expert Systems with Applications 36 (2009) 8368.

[54] B. Mehdizadeh, K. Movagharnejad, Chemical Engineering Research and Design 89 (2011) 2420.

[55] S.R. Gunn, ISIS technical report 14 (1998) 5.

[56] K.-R. Muller, S. Mika, G. Ratsch, K. Tsuda, B. Scholkopf, IEEE transactions on neural networks 12 (2001) 181.

[57] J.-S.R. Jang, C.-T. Sun, E. Mizutani, (1997).

[58] A. Baghban, M. Bahadori, J. Rozyn, M. Lee, A. Abbas, A. Bahadori, A. Rahimali, Applied thermal engineering 93 (2016) 1043.

[59] M. Afshar, A. Gholami, M. Asoodeh, Korean Journal of Chemical Engineering 31 (2014) 496. 
[60] A. Karkevandi-Talkhooncheh, S. Hajirezaie, A. Hemmati-Sarapardeh, M.M. Husein, K. Karan, M. Sharifi, Fuel 205 (2017) 34.

[61] A. Khosravi, R. Nunes, M. Assad, L. Machado, Journal of Cleaner Production (2018).

[62] K. Ahangari, S.R. Moeinossadat, D. Behnia, Soils and Foundations 55 (2015) 737.

[63] J. Kennedy, Springer, 2010.

[64] R. Eberhart, J. Kennedy, Micro Machine and Human Science, 1995. MHS'95., Proceedings of the Sixth International Symposium on, IEEE, 1995, p. 39-43.

[65] Y. Shi, R. Eberhart, Evolutionary Computation Proceedings, 1998. IEEE World Congress on Computational Intelligence., The 1998 IEEE International Conference on, IEEE, 1998, p. 69-73.

[66] J.-S. Chiou, S.-H. Tsai, M.-T. Liu, Simulation Modelling Practice and Theory 26 (2012) 49.

[67] A. Karkevandi-Talkhooncheh, A. Rostami, A. Hemmati-Sarapardeh, M. Ahmadi, M.M. Husein, B. Dabir, Fuel 220 (2018) 270.

[68] J.E. Onwunalu, L.J. Durlofsky, Computational Geosciences 14 (2010) 183.

[69] D. Fang, X. Zhang, Q. Yu, T.C. Jin, L. Tian, Journal of Cleaner Production 173 (2018) 143.

[70] M. Hosseinzadeh, A. Hemmati-Sarapardeh, Journal of Molecular Liquids 200 (2014) 340.

[71] P.J. Rousseeuw, A.M. Leroy, Robust regression and outlier detection. John wiley \& sons, 2005.

[72] A.H. Mohammadi, F. Gharagheizi, A. Eslamimanesh, D. Richon, Chemical engineering science 81 (2012) 1. 